
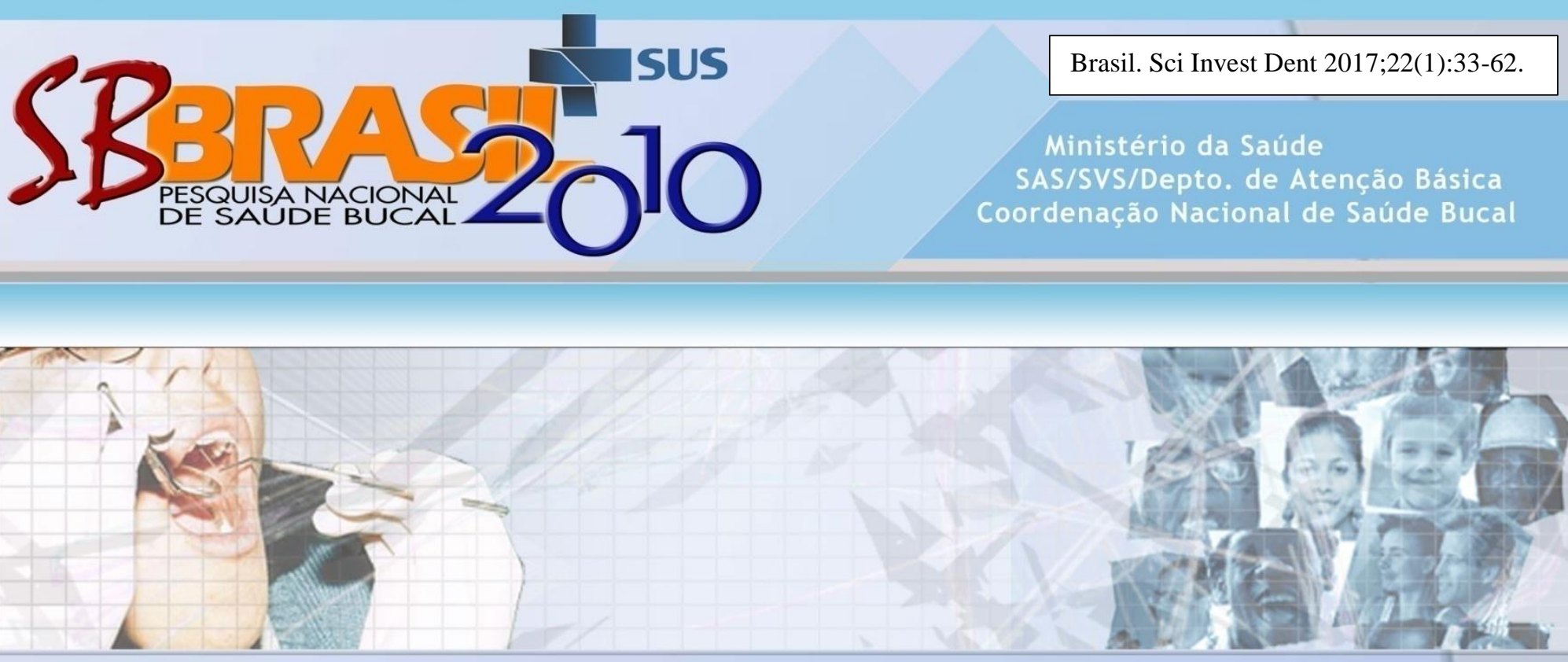

\title{
ANÁPOLIS-GO
}

\section{Brasília-DF 2011}




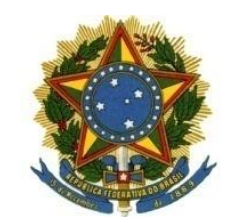

Ministério da Saúde

Secretaria de Atenção à Saúde

Departamento de Atenção Básica

Coordenação Nacional de Saúde Bucal

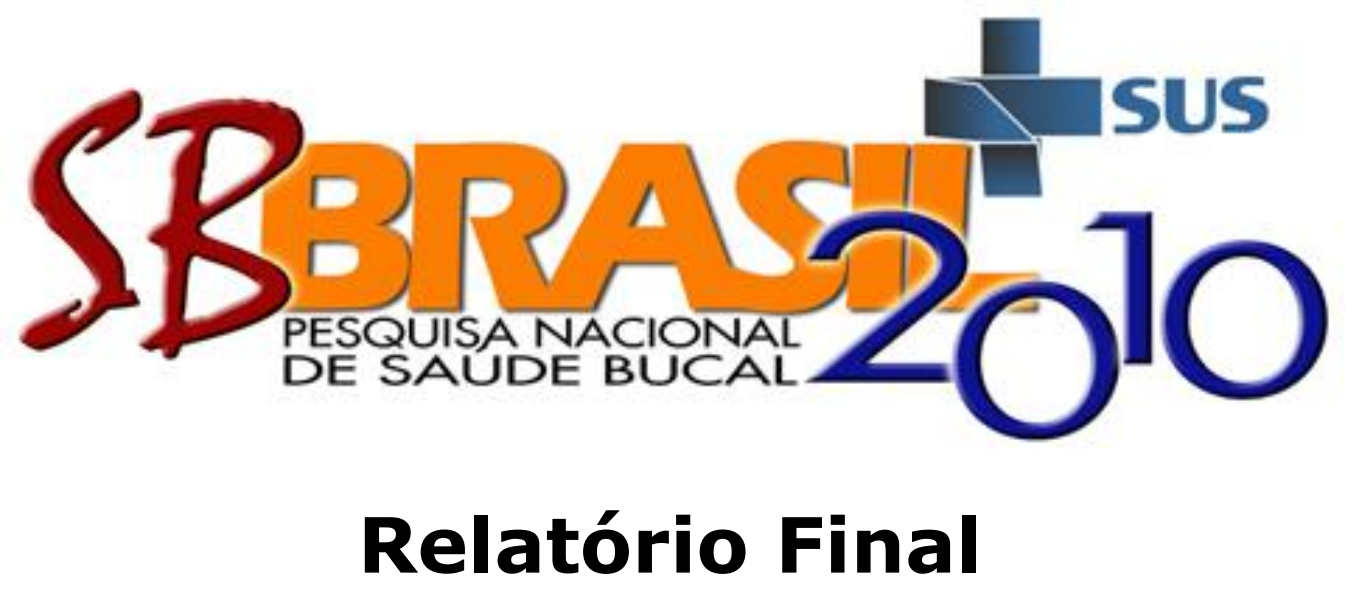

Município de Anápolis/GO

Anápolis,GO

Abril, 2012 


\section{Projeto SBBrasil 2010}

\section{Alexandre Rocha Santos Padilha}

Ministro da Saúde

Helvécio Miranda Magalhães Júnior

Secretário de Atenção à Saúde

Hêider Aurélio Pinto

Diretor do Departamento de Atenção Básica

Gilberto Alfredo Pucca Jr.

Coordenador Geral de Saúde Bucal

\section{Comitê Técnico Assessor em Vigilância em Saúde Bucal}

Gilberto Alfredo Pucca Jr.

Coordenação Nacional de Saúde Bucal

Angelo Giuseppe Roncalli da Costa Oliveira Universidade Federal do Rio Grande do Norte

Lenildo de Moura

Coord. Geral Doenças e Agravos Não-Transmissíveis/SVS

Marco Aurélio Peres

Universidade Federal de Santa Catarina

Maria do Carmo Matias Freire

Universidade Federal de Goiás

Maria IIma de Souza Gruppioni Côrtes

Pontifícia Universidade Católica de Minas Gerais

Mario Vianna Vettore

Escola Nacional de Saúde Pública - Fiocruz

Paulo Capel Narvai

Faculdade de Saúde Pública da USP

Paulo Sávio Angeiras de Góes

Universidade de Pernambuco

Samuel Jorge Moysés

Pontifícia Universidade Católica do Paraná
Coordenação Executiva do SBBrasil nos Centros Colaboradores e Ministério da Saúde

Cláudia Helena Soares de Morais Freitas

Centro Colaborador Univ. Fed. do Rio G. do Norte

Nilcema Figueiredo

Centro Colaborador Univ. de Pernambuco

Sandra Cristina Guimarães Bahia Reis

Centro Colaborador da Universidade Federal de Goiás

Rafaela da Silveira Pinto

Centro Colaborador Pontifícia Univ. Católica de Minas Gerais

Elisete Casotti

Centro Colaborador Escola Nacional de Saúde Pública

Regina Auxiliadora de Amorim Marques

Centro Colaborador Faculdade de Saúde Pública da USP

Antonio Carlos Nascimento

Centro Colaborador Pontifícia Universidade Católica do Paraná

Karen Glazer de Anselmo Peres

Centro Colaborador Universidade Federal de Santa Catarina

Moacir Paludetto Jr.

Coordenação de Saúde Bucal/DAB/SAS/MS

Lenildo de Moura

Coord. Geral Doenças e Agravos Não-Transmissíveis/SVS

\section{Coordenação Geral}

Angelo Giuseppe Roncalli da Costa Oliveira

Universidade Federal do Rio Grande do Norte - UFRN

\section{Assessoria em Amostragem}

Nilza Nunes da Silva

Faculdade de Saúde Pública da Universidade de São Paulo (FSP-USP)

\section{Realização:}

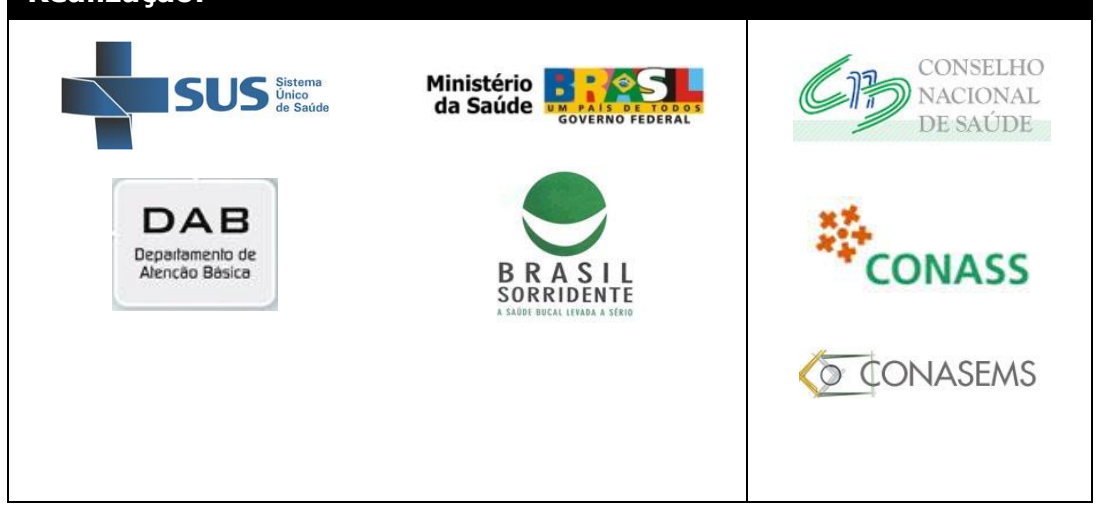

\section{Apoio:}

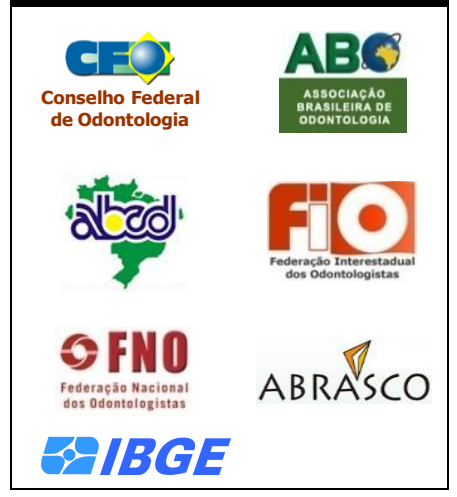




\section{Coordenação Técnica}

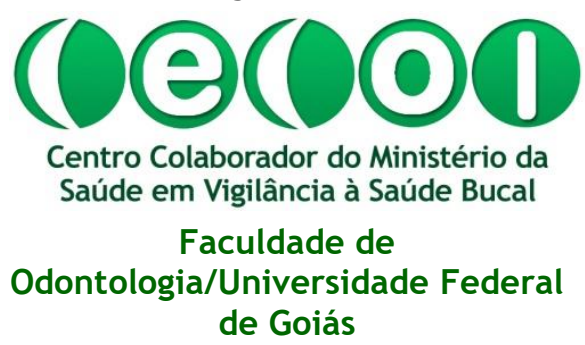

\section{Equipes de Coordenação Locais}

\section{Coordenação Estadual (Secretaria de Saúde de Goiás)}

Renata do Nascimento

\section{Coordenação Municipal (Secretaria Municipal de Saúde de Anápolis)}

Fabíola Soares Fernandes

\section{Equipes de Campo (Recursos humanos da Secretaria Municipal de Saúde de Anápolis)}

Examinadores
(Cirurgiões-dentistas)
Adriana Martins Braga
Beatriz de Souza Oliveira Batista
Camila Neiva Finotti
Lívia Jorge Naben
Luciana Machado Guimarães
Maria Angélica Magalhães Rodrigues
Marília Rodrigues dos Santos
Priscilla de Sousa Lima
Rosana Ferreira Morais

Anotadores Batedor

(Auxiliares de Saúde Bucal)

Tatiana Pereira Bernardo

Divino Carvalho

Emanuela Esteves César

Juliana Alves de Souza

Maria Conceição de Lima

Idna Paula Lourenço

Mayra Garcia de Castro Rocha

Vanusa Pacheco Macedo

Patrícia da Silva Brandão

Maria das Graças Rezende 


\section{Lista de Tabelas}

Tabela 1. Distribuição da amostra de acordo com sexo e grupo etário. Anápolis, GO. 2010. 44

Tabela 2. Distribuição da amostra de acordo com grupo etário e cor ou raça. Anápolis, GO. 2010........ 45

Tabela 3. Prevalência de cárie em dentição decídua (ceo) e permanente (CPO) de acordo com grupo etário. Anápolis, GO. 2010.

Tabela 4. Média do Índice ceo-d (5 anos), CPO-D (demais idades) e proporção dos componentes em relação ao ceo-d ou CPO-D total, segundo grupo etário. Anápolis, GO. 2010

Tabela 5. Média da condição de raiz e proporção dos componentes em relação ao total de raízes expostas, segundo grupo etário. Anápolis, GO. 2010.

Tabela 6. Médias das necessidades de tratamento para cárie dentária, segundo grupo etário. Anápolis, GO. 2010.

Tabela 7. Percentuais das necessidades de tratamento para cárie dentária, segundo grupo etário. Anápolis, GO. 2010

Tabela 8. Percentual de indivíduos segundo Condição Periodontal medida pelo Índice Periodontal Comunitário (CPI) e grupo etário. Anápolis, GO. 2010.

Tabela 9. Prevalência de Sangramento, Cálculo e Bolsa Periodontal Rasa e Profunda segundo grupo etário. Anápolis, GO. 2010...

Tabela 10. Índice de Perda de Inserção Periodontal (PIP) em percentuais de pior escore apresentado segundo grupo etário. Anápolis, GO. 2010.

Tabela 11. Condição de oclusão dentária analisada pelo Índice de Estética Dentária (DAI), segundo grupo etário. Anápolis, GO. 2010.

Tabela 12. Condição de oclusão dentária analisada pelo Índice de Estética Dentária (DAI), segundo grupo etário. Anápolis, GO. 2010.

Tabela 13. Uso de Prótese Dentária Superior segundo o tipo de prótese e grupo etário. Anápolis, GO. 2010.

Tabela 14. Uso de Prótese Dentária Inferior segundo o tipo de prótese e grupo etário. Anápolis, GO. 2010.

Tabela 15. Necessidade de Prótese Dentária segundo o tipo de prótese e grupo etário. Anápolis, GO. 2010.

Tabela 16. Prevalência de pelo menos um dente incisivo afetado por traumatismo em crianças de 12 anos. Anápolis, GO. 2010

Tabela 17. Média de dentes incisivos afetados por traumatismo em crianças de 12 anos. Anápolis, GO. 2010.

Tabela 18. Prevalência e gravidade da fluorose dentária aos 12 anos. Anápolis, Go. 2010.

Tabela 19. Morbidade dentária auto-referida, prevalência e gravidade da dor de dente segundo grupo etário. Anápolis, GO. 2010.

Tabela 20. Uso de serviços odontológicos segundo grupo etário. Anápolis, GO. 2010. 55

Tabela 21. Percepção de saúde bucal e avaliação do impacto das condições de saúde bucal sobre a vida diária (OIDP) segundo as dimensões do índice e grupo etário. Anápolis, GO. 2010. 56

\section{Lista de Figuras}

Figura 1. Médias dos componentes do ceo-d (5 anos) e CPO-D (demais grupos etários) de acordo com grupo etário. Anápolis, GO. 2010.

Figura 2. Médias e respectivos intervalos de confiança (95\%) do ceo-d (5 anos) e CPO-D (demais grupos etários) de acordo com grupo etário. Anápolis, GO. 2010. 


\section{Sumário}

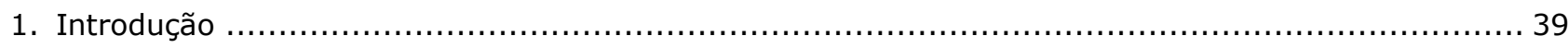

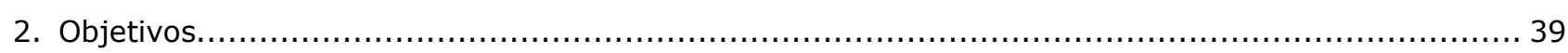

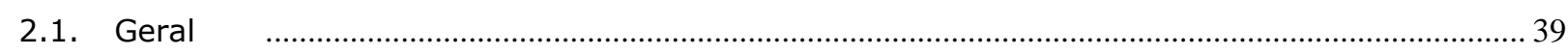

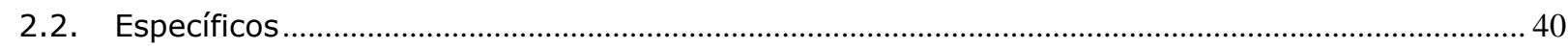

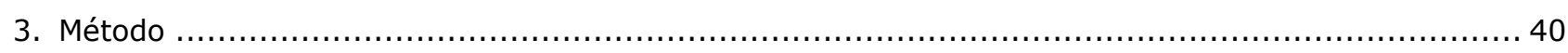

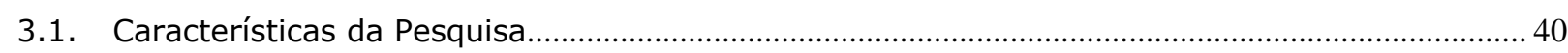

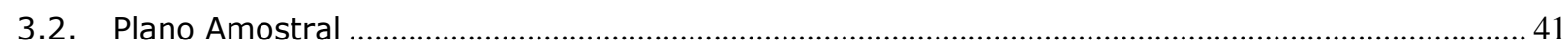

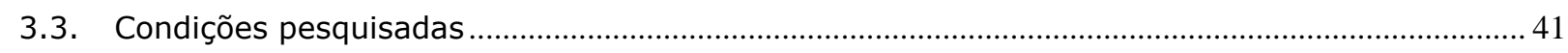

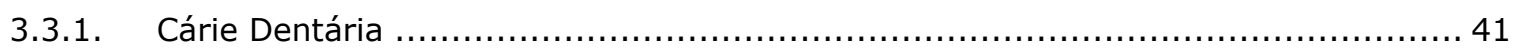

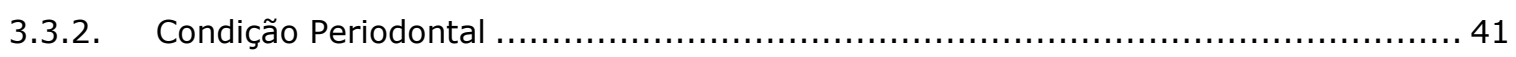

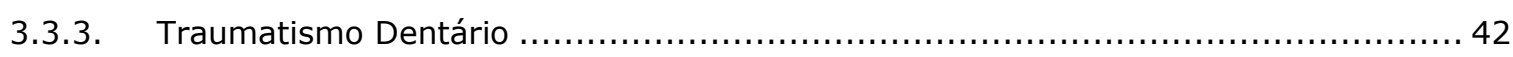

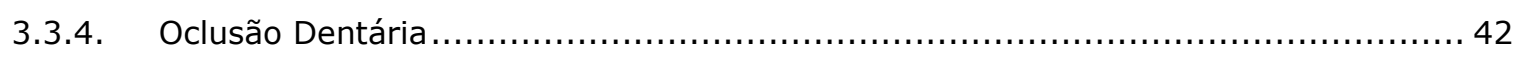

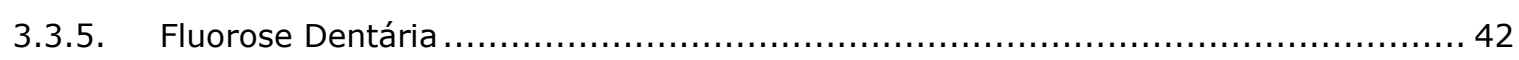

3.3.6. Edentulismo (Uso e necessidade de prótese) …......................................... 42

3.3.7. Condição socioeconômica, utilização de serviços odontológicos e autopercepção de saúde bucal................................................................................ 42

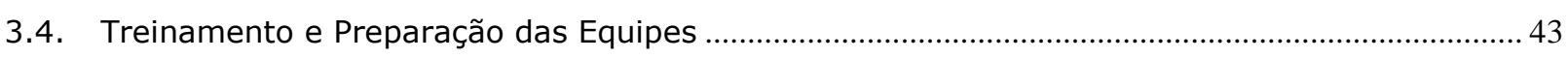

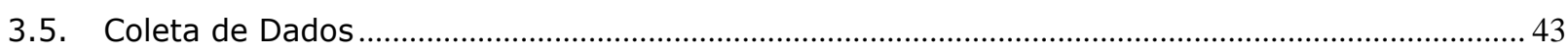

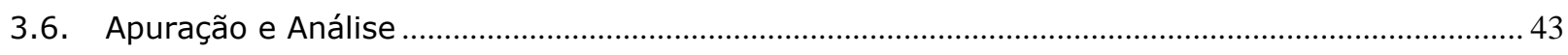

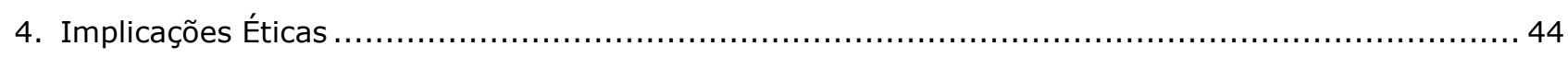

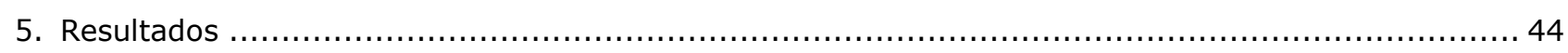

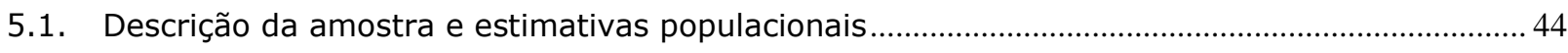

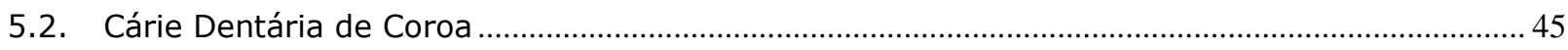

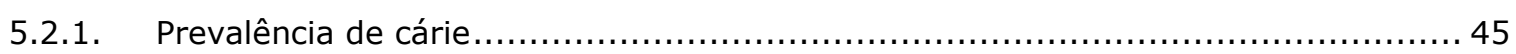

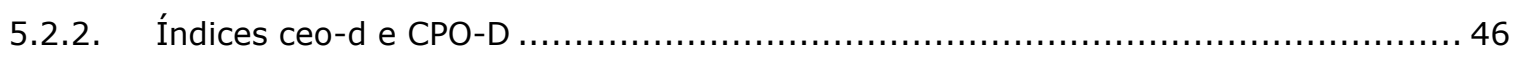

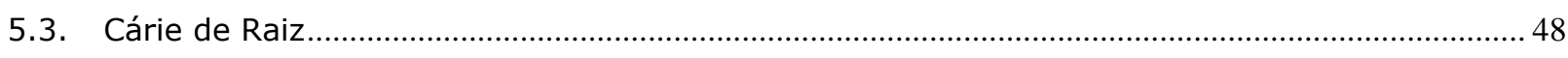

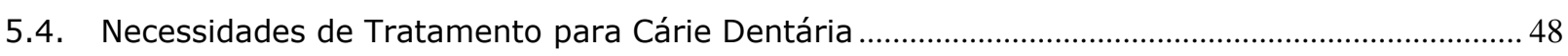

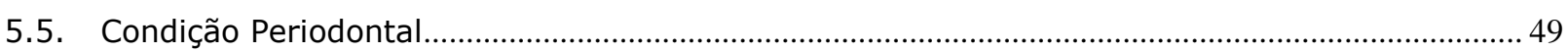

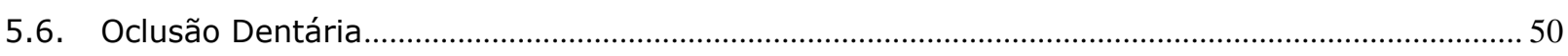

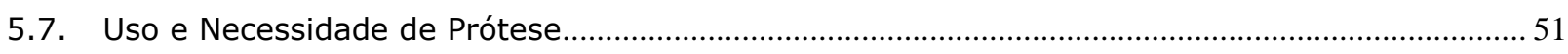

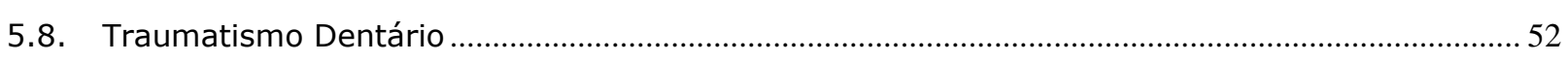

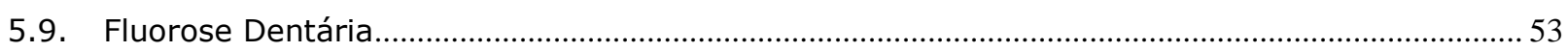

5.10. Morbidade dentária referida, uso de serviços odontológicos e impactos da saúde bucal

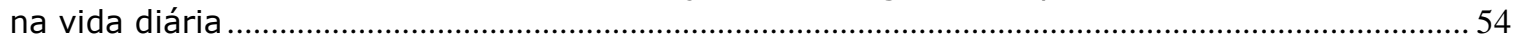

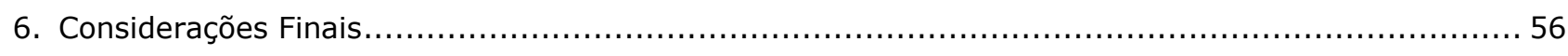

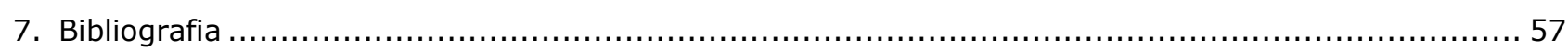

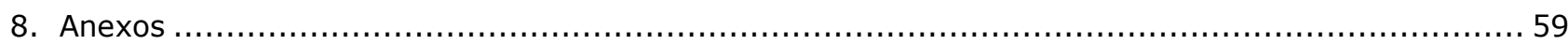




\section{Introdução}

Os estudos transversais são importantes componentes em qualquer política de vigilância em saúde. A despeito do constante aperfeiçoamento em nossos Sistemas de Informação, a partir dos quais se torna possível estabelecer um diagnóstico da situação de saúde da população, em muitas situações não há como prescindir de informações epidemiológicas obtidas a partir de dados primários. No caso particular da saúde bucal, o diagnóstico coletivo dos principais agravos (cárie dentária, doença periodontal, oclusopatias, dentre outros) deve ser estabelecido, com propriedade, mediante a realização de inquéritos populacionais.

Os três grandes levantamentos nacionais realizados em 1986, 1996 e 2003 foram de grande relevância para a construção de uma consistente base de dados relativa ao perfil epidemiológico de saúde bucal da população brasileira. Contudo, é fundamental que a realização destes estudos faça parte de uma estratégia inserida no componente de vigilância à saúde da Política de Saúde, na perspectiva da construção de uma série histórica de dados de saúde bucal com o objetivo de verificar tendências, planejar e avaliar serviços.

A Política Nacional de Saúde Bucal - Brasil Sorridente - se constitui num marco na história das Políticas Públicas no Brasil na medida em que incorpora uma agenda em discussão desde o Movimento pela Reforma Sanitária Brasileira e traduz, em seus pressupostos operacionais, os princípios do Sistema Único de Saúde. Ao trabalhar os eixos da atenção à saúde bucal a partir do incremento da atenção básica por meio da Estratégia Saúde da Família, da implementação dos Centros de Especialidades Odontológicas como elemento estruturante da atenção secundária, além das ações de caráter coletivo, o Brasil Sorridente se insere no conjunto de programas estratégicos na atual Política de Saúde.

Dentre os pressupostos dessa política, que visam à reorientação do modelo de atenção à saúde bucal, destacam-se: (a) "utilizar a Epidemiologia e as informações sobre o território subsidiando o planejamento" e (b) "centrar a atuação na Vigilância à Saúde, incorporando práticas contínuas de avaliação e acompanhamento dos danos, riscos e determinantes do processo saúde doença" (Brasil, 2004). Tais pressupostos devem, portanto, ser postos em prática a partir de diversas estratégias, dentre elas a realização de pesquisas epidemiológicas de base nacional.

Importante salientar que esta pesquisa faz parte do processo histórico que se ampliou e aprofundou com o Projeto SBBrasil 2003, o qual proporcionou um dos mais completos diagnósticos da saúde bucal dos brasileiros. Pretende-se, com este projeto, dar continuidade a esse processo, realizando uma pesquisa em moldes semelhantes, de maneira a construir uma série histórica, contribuindo para as estratégias de avaliação e planejamento dos serviços, ao mesmo tempo em que consolida um modelo metodológico e demarca o campo de atuação do componente de vigilância à saúde da Política Nacional de Saúde Bucal.

O relatório da Pesquisa Nacional de Saúde Bucal - Projeto SBBrasil 2010 foi publicado no corrente ano, incluindo os dados nacionais e regionais. Aqueles referentes aos domínios (capital e municípios do interior) foram apresentados somente para algumas das condições pesquisadas. Os relatórios das capitais deverão ser elaborados e divulgados individualmente. Da mesma forma, os municípios do interior que realizaram ampliação de sua amostra para obter dados representativos de sua população, deverão analisar e elaborar seus relatórios separadamente. Desse modo, o presente relatório descreve a metodologia e os resultados da Pesquisa Nacional de Saúde Bucal - Projeto SBBrasil 2010 no município de Anápolis, GO, que realizou ampliação do estudo para o município.

\section{Objetivos}

\subsection{Geral}

Conhecer a situação de saúde bucal da população urbana no município de Anápolis-GO em 2010, e subsidiar o planejamento e a avaliação das ações e serviços junto ao Sistema Único de Saúde. 


\subsection{Específicos}

a) Estimar, para a população de 5, 12, 15 a 19, 35 a 44 e 65 a 74 anos, a prevalência e a gravidade da cárie dentária em coroa e raiz.

b) Estimar, para a população de 12, 15 a 19, 35 a 44 e 65 a 74 anos, a prevalência, extensão e gravidade da doença periodontal.

c) Estimar, para a população de 5, 12 e 15 a 19 anos, a prevalência e a gravidade de oclusopatias.

d) Estimar, para a população de 12 anos, a prevalência e a gravidade da fluorose dentária.

e) Estimar, para a população de 12 anos, a prevalência de traumatismo dentário (fratura coronária e avulsão).

f) Estimar as necessidades de tratamento relacionadas com a cárie dentária.

g) Estimar a necessidade e uso de prótese nas faixas etárias de 15 a 19, 35 a 44 e 65 a 74 anos.

h) Estimar, para a população de 15 a 19, 35 a 44 e 65 a 74 anos, a prevalência e a gravidade da dor de origem dentária.

i) Obter dados que contribuam para caracterizar o perfil socioeconômico, a utilização de serviços odontológicos, a autopercepção e os impactos da saúde bucal.

\section{Método}

\subsection{Características da Pesquisa}

Do ponto de vista de organização geral, o SBBrasil 2010 se constitui em uma pesquisa de base nacional, com representatividade para as capitais de Estado e do Distrito Federal e para as cinco regiões naturais (Norte, Nordeste, Sudeste, Sul e Centro-Oeste). Compõe um estudo com base em uma amostra de indivíduos residentes em 177 municípios, nos quais foram realizados exames bucais para avaliar a prevalência e a gravidade dos principais agravos bucais e aplicados questionários para coleta de dados sobre a condição socioeconômica, utilização de serviços odontológicos e percepção de saúde.

Com relação ao componente operacional, a pesquisa foi um estudo coordenado e financiado pelo Ministério da Saúde, contando com a participação articulada das Secretarias de Atenção à Saúde (SAS) e de Vigilância à Saúde (SVS). Na execução, teve a participação ativa das Secretarias Estaduais e Municipais de Saúde e contou com o apoio de entidades de classe odontológicas, universidades e institutos de pesquisa, articulados pela Coordenação Nacional de Saúde Bucal, por intermédio do seu Comitê Técnico Assessor para Vigilância em Saúde Bucal (CTA) e dos Centros Colaboradores em Vigilância em Saúde Bucal (Cecol). O Projeto teve, ainda, o apoio da Associação Brasileira de Pós-Graduação em Saúde Coletiva (Abrasco) e a colaboração do Instituto Brasileiro de Geografia e Estatística (IBGE).

Para a operacionalização do projeto foram desenvolvidos manuais específicos, nos quais podem ser encontrados maiores detalhes a respeito da metodologia da pesquisa. O Manual do Coordenador contém as instruções gerais para que o coordenador municipal pudesse conduzir a pesquisa localmente, incluindo informações sobre o desenho amostral, as atribuições das equipes e o fluxograma operacional, além das estratégias de supervisão de campo. O Manual da Equipe de Campo traz as informações necessárias para o trabalho de campo, como as formas de percurso e arrolamento dos domicílios e a descrição das variáveis utilizadas. No Manual de Calibração de Examinadores constam as informações gerais para que os responsáveis pelo treinamento das equipes locais pudessem realizar o processo de calibração de todos os índices utilizados. Todo esse material está disponível para download no sítio da Coordenação Nacional de Saúde Bucal (http://dab.saude.gov.br/portaldab/ape_brasil_sorridente.php?conteudo=vigilancia_epidemiol ogica). 


\subsection{Plano Amostral}

O Plano Amostral constou de domínios relativos às capitais e municípios do interior. Cada capital de Unidade da Federação (Estados e Distrito Federal) compôs um domínio e todos os municípios do interior de cada região outro domínio, representativo dos municípios do interior. Ao todo, são 27 domínios geográficos de capital, mais 5 de interior, um para cada região, totalizando 32 domínios. As Unidades Primárias de Amostragem (UPA) foram: (a) município, para o interior das regiões e (b) setor censitário para as capitais. Os setores censitários sorteados em Anápolis estão no Anexo 1. Foram entrevistados e examinados em seus domicílios indivíduos nas idades de 5 anos e de 12 anos e pertencentes aos grupos etários de 15 a 19 anos, 35 a 44 anos e 65 a 74 anos.

O detalhamento do processo de amostragem, com os procedimentos e cálculos utilizados, encontra-se disponível no relatório nacional do Projeto SB Brasil.

\subsection{Condições pesquisadas}

A manutenção de uma base metodológica uniforme é um requisito importante quando se considera a realização de estudos seccionais como um componente de destaque nas estratégias de vigilância da saúde bucal.

Os índices utilizados no SB Brasil 2010 e os acréscimos ou modificações atendem às recomendações da OMS na $4^{a}$ edição de seu Manual de Instruções para Levantamento Epidemiológico Básico em Saúde Bucal (WHO, 1997) e levam em conta a experiência acumulada no Brasil, em várias regiões, notadamente a partir dos anos 1980.

Além dos índices tradicionais para aferição dos agravos bucais, também foi aplicado, aos indivíduos examinados, um questionário contendo questões relativas à caracterização socioeconômica, utilização de serviços odontológicos e morbidade bucal autoreferida e autopercepção de saúde bucal.

Apresentam-se a seguir, de modo resumido, as condições observadas pelos examinadores do SBBrasil 2010, os índices adotados e algumas alterações propostas para o estudo. A ficha de exame encontra-se no Anexo 2. Maiores detalhes sobre os códigos, critérios e técnicas de aplicação dos índices podem ser obtidos nos manuais técnicos elaborados para subsidiar as equipes de campo e coordenação e disponíveis no já citado sítio eletrônico do projeto (http://dab.saude.gov.br/portaldab/ape_brasil_sorridente.php?conteudo=vigilancia_epidemiol ogica).

\subsubsection{Cárie Dentária}

Para a condição dentária, foi utilizado o índice preconizado pela OMS (WHO, 1997), de onde se pode inferir o CPO-D médio (dentição permanente) e o ceo-d (dentição decídua). O CPO-D/ceod expressam a soma dos dentes cariados, perdidos e obturados. Através do registro das necessidades de tratamento, pôde-se identificar, além necessidades propriamente ditas, a presença de lesões não cavitadas (mancha branca presente) e os diferentes níveis da doença ativa (cárie de esmalte, cárie de dentina e cárie próxima à polpa). Dessa forma, uma maior qualificação do índice pode ser proporcionada pela combinação das distintas medidas de necessidades de tratamento.

\subsubsection{Condição Periodontal}

O índice mais utilizado em inquéritos populacionais para a aferição da condição periodontal tem sido o CPI (Índice Periodontal Comunitário), proposto pela OMS (Holmgren, 1994) complementado pelo exame da Perda de Inserção Periodontal (PIP) para população adulta e idosa. O CPI verifica a ocorrência de sangramento, cálculo e presença de bolsa periodontal (rasa e profunda) tendo como referência o exame por sextante (grupos de 6 dentes entre os 32 da arcada dentária). 
Especificamente com relação ao CPI, o modo de aferição foi modificado no sentido de obter a prevalência individualizada dos agravos (sangramento, cálculo e bolsa). Tratou-se de uma estratégia importante, pois o CPI tradicional, ao referir apenas o pior escore do sextante, em geral tende a mascarar a real prevalência desses agravos.

\subsubsection{Traumatismo Dentário}

Embora na aferição da condição dentária os dentes que apresentem lesões traumáticas sejam codificados (código "T" do CPO), há uma nítida perda de informação, particularmente por dois aspectos. Em primeiro lugar nos casos em que há uma lesão de cárie associada, perde-se a informação do trauma, uma vez que prevalece a informação de cárie dentária. Em segundo lugar a informação é demasiadamente simplificada, podendo uma pequena fratura ser codificada do mesmo modo que uma perda de estrutura dentária de maiores proporções. Além disso, não é possível saber quando o dente é perdido por trauma, pois o mesmo código é usado para perdas por outros motivos.

Desse modo, julgou-se importante que o traumatismo dentário fosse avaliado como uma medida específica, em separado, na idade de 12 anos. Para tanto foram utilizados os critérios que indicavam sinais de fratura coronária e avulsão dentária. Para este exame, foram considerados os incisivos superiores e inferiores permanentes.

\subsubsection{Oclusão Dentária}

Em sua quarta edição, o Manual da OMS (WHO, 1997) propôs um novo índice de avaliação de oclusopatias, proposto anos antes por Cons e colaboradores (Cons et al, 1989), chamado DAI (sigla derivada da expressão inglesa 'Dental Aesthetic Index'). O princípio básico do DAI é de uma combinação de medidas (não somente de problemas oclusais) as quais, em seu conjunto, expressam o estado oclusal do indivíduo e, consequentemente, sua necessidade de tratamento, devido à composição do índice que considera comprometimento estético além da oclusão. Ao todo são obtidas 11 medidas, considerando-se três grandes dimensões a serem avaliadas: a dentição, o espaço e a oclusão propriamente dita.

Desse modo, no presente inquérito, o Índice de Estética Dental (DAI) foi utilizado para avaliação das anormalidades dentofaciais, na idade de 12 anos e na faixa etária de 15 a 19 anos. A oclusão na dentição decídua foi avaliada com o emprego do índice de Foster e Hamilton (Foster \& Hamilton, 1969).

\subsubsection{Fluorose Dentária}

A classificação conhecida como Índice de Dean (Dean, 1934) tem sido usada por muitos anos para descrever a fluorose o que permite a comparação com um volume maior de estudos. É o índice recomendado pela OMS para estudos de fluorose dentária em populações (WHO, 1997). Além disso, dada a alta subjetividade envolvida na aferição dessa condição, é o instrumento epidemiológico de escolha para inquéritos populacionais, tendo em vista a obtenção de melhores níveis de reprodutibilidade, em relação a outros índices.

\subsubsection{Edentulismo (Uso e necessidade de prótese)}

A avaliação do uso e necessidade de prótese ajuda a entender o agravo "edentulismo", servindo, ao mesmo tempo, para estimar a gravidade do problema pela análise conjunta dos dados de uso e necessidade e para subsidiar ações de planejamento a partir da análise das necessidades.

\subsubsection{Condição socioeconômica, utilização de serviços odontológicos e autopercepção de saúde bucal}

Para pesquisa dessas variáveis, foi utilizado questionário composto por três blocos: (a) caracterização demográfica e socioeconômica; (b) utilização de serviços odontológicos e 
morbidade bucal referida; (c) autopercepção e impactos em saúde bucal. As perguntas foram aplicadas ao responsável pelo domicílio para obtenção de informações relativas à família e aos menores de idade e ao próprio indivíduo examinado quando maior de idade.

\subsection{Treinamento e Preparação das Equipes}

As equipes de campo, formadas por um examinador e um anotador, foram treinadas em oficinas de trabalho com duração de 32 horas. As capitais contaram com 10 equipes de campo e os municípios do interior com 2 a 6 equipes, dependendo do porte populacional. Em Anápolis, as equipes foram compostas por profissionais da Secretaria Municipal de Saúde do município, sendo 09 cirurgiões dentistas, que atuaram como examinadores, e 09 auxiliares em saúde bucal, que atuaram como anotadoras.

Os objetivos da oficina foram: (a) detalhar a operacionalização das etapas do trabalho, (b) compreender as atribuições de cada participante, (c) discutir aspectos teóricos e práticos dos índices a serem utilizados e (d) assegurar um grau aceitável de uniformidade nos procedimentos.

Em cada oficina de treinamento participaram até 10 equipes ao mesmo tempo, entretanto, nos turnos planejados para realização dos exames, as equipes foram divididas em dois grupos cada um com um instrutor de calibração. Os procedimentos de calibração foram planejados de modo a antecipar (simular) as condições que os examinadores encontrariam, sobretudo em relação às condições estudadas e aos diferentes grupos populacionais.

A técnica de calibração adotada foi a do consenso (Frias et al, 2004), calculando-se os coeficientes de concordância entre cada examinador e os resultados obtidos pelo consenso da equipe. Tomou-se como referência o modelo proposto pela OMS (WHO, 1993) e foi calculado o coeficiente Kappa ponderado para cada examinador, grupo etário e agravo estudado, tendo como limite mínimo aceitável, o valor de 0,65. Os valores do Kappa ponderado em Anápolis, para os diferentes agravos, idades e faixa etárias foram os seguintes: para a cárie de coroa variou entre 0,84 a 0,99. Para fluorose, de 0,75 a 0,91; para o CPI, de 0,76 a 1,00; para o DAI, variou de 0,90 a 1,00 e para traumatismo de 0,83 a 0,99 Os resultados mostraram concordância boa/substancial a quase perfeita para todas as condições investigadas.

\subsection{Coleta de Dados}

Os dados foram coletados com o emprego de um dispositivo eletrônico (Personal Digital Assistant - PDA), os quais foram cedidos para o SBBrasil 2010 pelo IBGE para uso durante o trabalho de campo. Um software específico para a entrada de dados foi desenvolvido por uma empresa especializada e instalado em todos os aparelhos. Cada equipe tinha um PDA disponível de modo que $o$ uso de fichas em papel ocorreu somente em situações excepcionais e apenas como alternativa ao sistema do PDA.

\subsection{Apuração e Análise}

O uso do PDA permitiu que os bancos de dados fossem produzidos durante a própria coleta. Após a finalização dos trabalhos da equipe de campo, os arquivos foram transferidos dos PDA para computadores, que fizeram a conversão em arquivos DBF. Após a verificação de inconsistências, os arquivos foram convertidos para o formato do software padrão que foi utilizado para as análises. Os dados obtidos em fichas tradicionais foram digitados em software desenvolvido em linguagem Fox Base, nos quais foram estabelecidos mecanismos de controle de qualidade na entrada dos dados. Do mesmo modo que os arquivos dos PDA, foram corrigidas as inconsistências e, em seguida, foram convertidos para a plataforma de análise.

Com relação à análise dos dados, considerando-se que se trata de amostra complexa, as estimativas de médias, prevalências e respectivos erros padrão foram calculadas com o uso do módulo "Complex Samples" do programa Statistical Package for the Social Science (SPSS), que considera as variáveis de planejamento e inclusão dos pesos básicos resultantes do processo de 
amostragem (SPSS, 2006). Os pesos amostrais foram calculados, para cada indivíduo examinado, a partir das probabilidades obtidas nos diferentes estágios de sorteio.

\section{Implicações Éticas}

Em acordo com a Resolução 196/96 do Conselho Nacional de Saúde (CNS), relativa às pesquisas em seres humanos (Brasil, 1999), o Projeto SBBrasil 2010 foi submetido ao Comitê de Ética em Pesquisa do Ministério da Saúde, sendo aprovado e recebendo registro na Comissão Nacional de Ética em Pesquisa (CONEP), do CNS, sob o número 15.498. Cópia do Projeto, do Termo de Consentimento Livre e Esclarecido (TCLE) utilizado e do parecer do CONEP estão disponíveis no sítio eletrônico do projeto (http://dab.saude.gov.br/portaldab/ape_brasil_sorridente.php?conteudo=vigilancia_epidemiol ogica). O TCLE encontra-se também no Anexo 3.

\section{Resultados}

Os resultados serão expressos a seguir de acordo com o tipo de agravo estudado, bem como os dados relativos ao questionário aplicado. Inicialmente será ilustrada a distribuição da amostra com relação às suas características demográficas e, em cada agravo, a análise será feita considerando os grupos etários estudados.

As variáveis de natureza quantitativa estão expressas na forma de médias e as variáveis categóricas na forma de frequência percentual. Para ambos os casos, em algumas situações será também ilustrado o respectivo intervalo de confiança para um $\alpha$ de $5 \%$ (I.C. $95 \%$ ) considerando os limites inferior (L.I.) e superior (L.S.).

Embora em algumas tabelas esses valores de intervalo de confiança estejam expressos para todas as medidas, é importante destacar que, para os valores de prevalência mais baixos (abaixo de $10 \%$ aproximadamente) as estimativas intervalares têm pouca aplicabilidade, conforme descrição do plano amostral.

\subsection{Descrição da amostra e estimativas populacionais}

Em Anápolis foram examinados 929 indivíduos. As Tabelas 1 e 2 ilustram a distribuição da amostra com relação à faixa etária, sexo e cor ou raça auto-relatada. Em todas as idades mais da metade da amostra foi composta pelo gênero feminino, exceto para a idade de 5 anos, em que houve paridade.

Tabela 1. Distribuição da amostra de acordo com sexo e grupo etário. Anápolis-GO, 2010.

\begin{tabular}{lcccccc}
\hline \hline & \multicolumn{4}{c}{ Sexo } & \multirow{2}{*}{ Total } \\
\cline { 2 - 6 } Grupo Etário & \multicolumn{3}{c}{ Masculino } & \multicolumn{2}{c}{ Feminino } & \\
\cline { 2 - 6 } & $\mathrm{n}$ & $\%$ & $\mathrm{~N}$ & $\%$ & $\mathrm{n}$ & $\%$ \\
\hline \hline 5 anos & $\mathbf{8 8}$ & 50,0 & $\mathbf{8 8}$ & 50,0 & 176 & 100,0 \\
12 anos & $\mathbf{8 9}$ & 47,3 & $\mathbf{9 9}$ & 52,7 & 188 & 100,0 \\
15 a 19 anos & $\mathbf{7 0}$ & 46,4 & $\mathbf{8 1}$ & 53,6 & 151 & 100,0 \\
35 a 44 anos & $\mathbf{9 2}$ & 37,6 & $\mathbf{1 5 3}$ & 62,4 & 245 & 100,0 \\
65 a 74 anos & $\mathbf{7 5}$ & 44,4 & $\mathbf{9 4}$ & 55,6 & 169 & 100,0 \\
\hline \hline Total & $\mathbf{4 1 4}$ & 44,6 & $\mathbf{5 1 5}$ & 55,4 & 929 & 100,0 \\
\hline \hline
\end{tabular}


Na Tabela 2 observa-se que o grupo etário de 65 a 74 anos foi o único em que a auto-declaração da raça foi predominantemente branca $(43,8 \%)$, nos demais os maiores percentuais foram para a raça parda.

Tabela 2. Distribuição da amostra de acordo com grupo etário e cor ou raça. Anápolis-GO, 2010.

\begin{tabular}{|c|c|c|c|c|c|c|c|c|c|c|c|c|}
\hline \multirow[b]{3}{*}{ Grupo Etário } & \multicolumn{10}{|c|}{ Cor ou Raça } & \multirow{2}{*}{\multicolumn{2}{|c|}{ Total }} \\
\hline & \multicolumn{2}{|c|}{ Branca } & \multicolumn{2}{|c|}{ Preta } & \multicolumn{2}{|c|}{ Amarela } & \multicolumn{2}{|c|}{ Parda } & \multicolumn{2}{|c|}{ Indígena } & & \\
\hline & $\mathrm{N}$ & $\%$ & $\mathrm{n}$ & $\%$ & $\mathrm{~N}$ & $\%$ & $\mathrm{~N}$ & $\%$ & $\mathrm{n}$ & $\%$ & $\mathrm{~N}$ & $\%$ \\
\hline 5 anos & 79 & 44,9 & 6 & 3,4 & 4 & 2,3 & 85 & 48,3 & 2 & 1,1 & 176 & 100,0 \\
\hline 12 anos & 57 & 30,3 & 9 & 4,8 & 9 & 4,8 & 113 & 60,1 & 0 & 0,0 & 188 & 100,0 \\
\hline 15 a 19 anos & 57 & 37,7 & 13 & 8,6 & 6 & 4,0 & 73 & 48,3 & 2 & 1,3 & 151 & 100,0 \\
\hline 35 a 44 anos & 80 & 32,7 & 25 & 10,2 & 12 & 4,9 & 128 & 52,2 & 0 & 0,0 & 245 & 100,0 \\
\hline 65 a 74 anos & 74 & 43,8 & 24 & 14,2 & 8 & 4,7 & 63 & 37,3 & 0 & 0,0 & 169 & 100,0 \\
\hline Total & 347 & 37,4 & 77 & 8,3 & 39 & 4,2 & 462 & 49,7 & 4 & 0,4 & 929 & 100,0 \\
\hline
\end{tabular}

\subsection{Cárie Dentária de Coroa}

As Tabelas 3 e 4 e Figuras 1 e 2 mostram os resultados relativos à prevalência e gravidade da cárie dentária em dentes decíduos e permanentes.

\subsubsection{Prevalência de cárie}

A Tabela 3 mostra a prevalência de cárie, medida pela proporção de ceo-d ou CPO-D maior ou igual a "1". Em Anápolis, 30\% das crianças aos 12 anos de idade apresentaram todos os dentes hígidos. Quase a totalidade dos grupos etários de adultos e idosos apresentou experiência de cárie, com mais de um dente afetado.

Tabela 3. Prevalência de cárie em dentição decídua (ceo) e permanente (CPO) de acordo com grupo etário. Anápolis-GO, 2010.

\begin{tabular}{|c|c|c|c|c|c|c|c|c|}
\hline \multirow[b]{3}{*}{ Grupo Etário } & \multicolumn{4}{|c|}{ ceo-d/CPO-D = 0} & \multicolumn{4}{|c|}{ ceo-d/CPO-D $\geq 1$} \\
\hline & \multirow[b]{2}{*}{$\mathrm{n}$} & \multirow[b]{2}{*}{$\%$} & \multicolumn{2}{|c|}{ IC $(95 \%)$} & \multirow[b]{2}{*}{$\mathrm{N}$} & \multirow[b]{2}{*}{$\%$} & \multicolumn{2}{|c|}{ IC $(95 \%)$} \\
\hline & & & L.I. & L.S. & & & L.I. & L.S. \\
\hline 5 anos & 80 & 41,4 & 34,3 & 48,8 & 96 & 58,6 & 51,2 & 65,7 \\
\hline 12 anos & 63 & 30,0 & 20,0 & 42,4 & 125 & 70,0 & 57,6 & 80,0 \\
\hline 15 a 19 anos & 31 & 19,8 & 13,5 & 28,0 & 120 & 80,2 & 72,0 & 86,5 \\
\hline 35 a 44 anos & 2 & 0,8 & 0,2 & 3,1 & 243 & 99,2 & 96,9 & 99,8 \\
\hline 65 a 74 anos & 2 & 0,7 & 0,2 & 3,2 & 167 & 99,3 & 96,8 & 99,8 \\
\hline
\end{tabular}




\subsection{2. Índices ceo-d e CPO-D}

$\mathrm{Na}$ Tabela 4 podem ser visualizados os resultados para dentição decídua (índice ceo-d) e permanente (índice CPO-D). A média de ceo-d e CPO-D para as idades de 5 anos e 12 anos, respectivamente, foi igual a 2,5. Para os mais jovens o maior problema são as cáries não tratadas, já para as crianças aos 12 anos o componente que mais contribui na composição do CPO-D é o dos dentes restaurados. E essa tendência se segue para os demais grupos. Com o avançar da idade, tanto para os adolescentes quanto para os adultos, a maior prevalência também é atribuída aos dentes restaurados. Entre os idosos o maior problema é a perda dentária.

Tabela 4. Média do Índice ceo-d ( 5 anos), CPO-D (demais idades) e proporção dos componentes em relação ao ceo-d ou CPO-D total, segundo grupo etário. Anápolis, GO. 2010

\begin{tabular}{|c|c|c|c|c|c|c|c|c|c|c|c|c|c|}
\hline \multirow[b]{3}{*}{ Grupo Etário } & \multirow[b]{3}{*}{$\mathrm{N}$} & \multirow{3}{*}{$\begin{array}{l}\text { Hígido } \\
\text { Média }\end{array}$} & \multicolumn{8}{|c|}{ Componentes do ceo-d/CPO-D } & \multirow{2}{*}{\multicolumn{3}{|c|}{$\begin{array}{l}\text { ceo-d/CPO-D } \\
\text { IC }(95 \%) \\
\end{array}$}} \\
\hline & & & \multicolumn{2}{|c|}{ Cariado } & \multicolumn{2}{|c|}{ Obt/Cariado } & \multicolumn{2}{|c|}{ Obturado } & \multicolumn{2}{|c|}{ Perdido } & & & \\
\hline & & & Média & $\%$ & Média & $\%$ & Média & $\%$ & Média & $\%$ & Média & L.I. & L.S. \\
\hline 5 anos & 176 & 16,4 & 1,8 & 72,1 & 0,1 & 5,6 & 0,5 & 21,1 & 0,0 & 1,2 & 2,5 & 2,0 & 3,0 \\
\hline 12 anos & 188 & 22,9 & 0,9 & 36,1 & 0,1 & 3,2 & 1,5 & 59,0 & 0,0 & 1,2 & 2,5 & 2,0 & 3,0 \\
\hline 15 a 19 & 151 & 23,6 & 1,0 & 24,2 & 0,1 & 2,4 & 2,8 & 69,4 & 0,2 & 4,2 & 4,1 & 3,4 & 4,8 \\
\hline $35 a$ & 245 & 12,1 & 1,3 & 7,3 & $\mathbf{0}$ & 2,3 & 8,5 & 47,0 & 7,8 & 43,3 & 18,0 & 17,0 & 19,0 \\
\hline 65 a 74 anos & 169 & 2, & 0,3 & 1,0 & 0,1 & 0,2 & 1,5 & 5,3 & 27,0 & 93,5 & 28,9 & 27,9 & 29,9 \\
\hline
\end{tabular}


As Figuras 1 e 2 mostram as médias dos componentes do ceo-d e CPO-D e os intervalos de confiança de todos os grupos etários pesquisados.

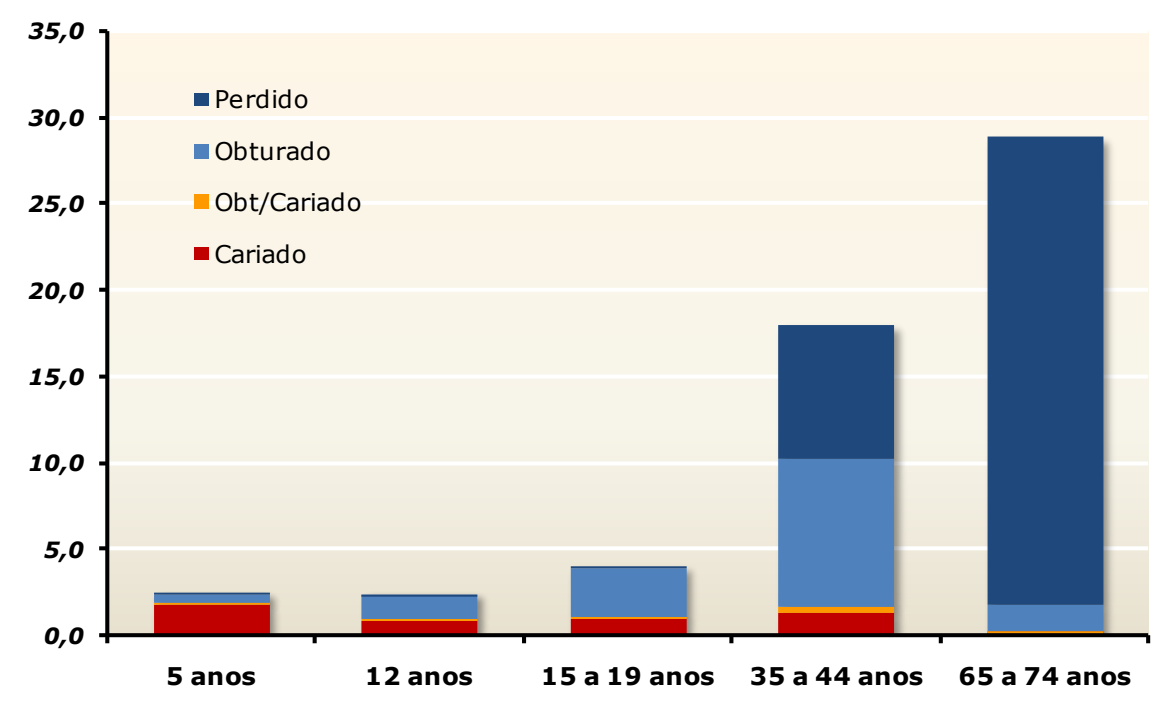

Figura 1. Médias dos componentes do ceo-d (5 anos) e CPO-D (demais grupos etários) de acordo com grupo etário. Anápolis-GO, 2010.

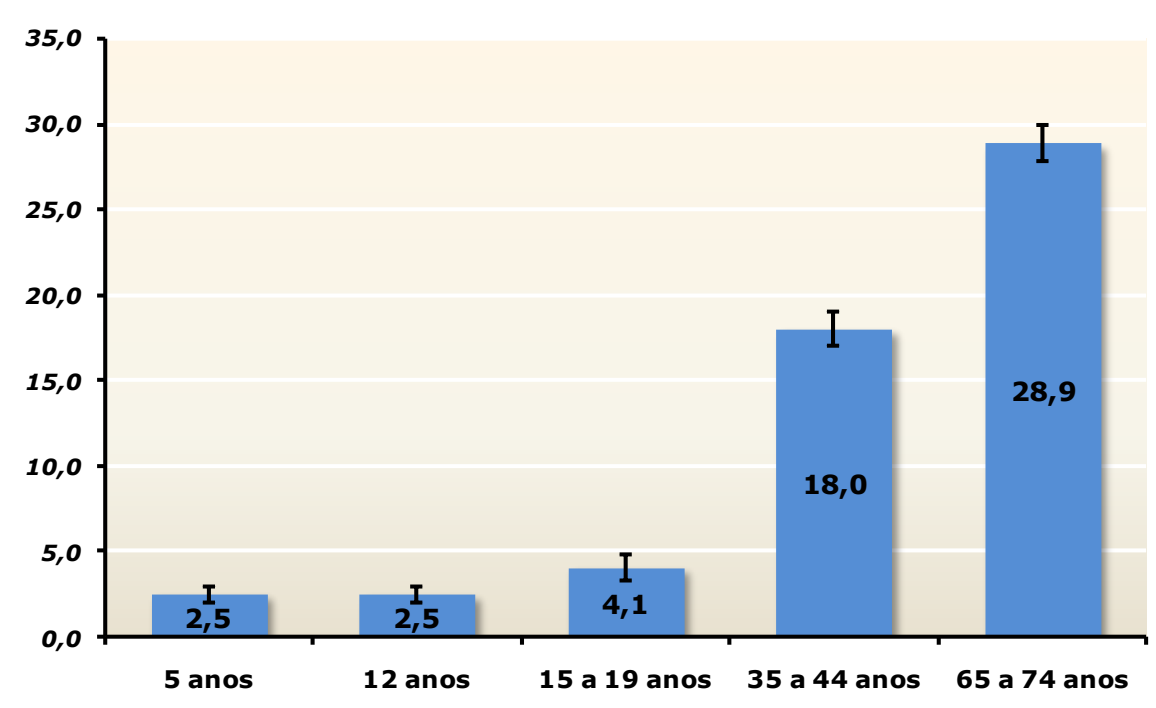

Figura 2. Médias e respectivos intervalos de confiança (95\%) do ceo-d ( 5 anos) e CPO-D (demais grupos etários) de acordo com grupo etário. Anápolis-GO, 2010. 


\subsection{Cárie de Raiz}

A Tabela 5 traz os resultados para cárie de raiz em adultos e idosos. De um modo geral, considerando as grandes perdas dentárias nestes dois grupos etários, pode-se perceber que a prevalência de cárie de raiz se apresenta baixa e a grande maioria das raízes expostas se encontra hígida.

Tabela 5. Média da condição de raiz e proporção dos componentes em relação ao total de raízes expostas, segundo grupo etário. Anápolis, GO. 2010

\begin{tabular}{|c|c|c|c|c|c|c|c|c|c|c|c|c|c|}
\hline \multirow[b]{3}{*}{$\begin{array}{l}\text { Grupo } \\
\text { Etário }\end{array}$} & \multirow[b]{3}{*}{$n$} & \multirow{3}{*}{$\begin{array}{l}\text { Hígida } \\
\text { Média }\end{array}$} & \multicolumn{8}{|c|}{ Componentes da Cárie de Raiz } & \multirow{2}{*}{\multicolumn{3}{|c|}{$\begin{array}{l}\text { Total de Raízes } \\
\text { Expostas } \\
\text { IC }(95 \%)\end{array}$}} \\
\hline & & & \multicolumn{2}{|c|}{ Cariada } & \multicolumn{2}{|c|}{ Obt/Cariada } & \multicolumn{2}{|c|}{ Obturada } & \multicolumn{2}{|c|}{$\begin{array}{c}\text { Apoio de } \\
\text { Ponte / } \\
\text { Coroa }\end{array}$} & & & \\
\hline & & & Média & $\%$ & Média & $\%$ & Média & $\%$ & Média & $\%$ & Média & L.I. & L.S. \\
\hline $\begin{array}{l}35 \text { a } 44 \\
\text { anos }\end{array}$ & 245 & 5,91 & 0,18 & 2,9 & 0,02 & 0,3 & 0,06 & 1,0 & 0,04 & 0,6 & 6,21 & 2,47 & 9,95 \\
\hline $\begin{array}{l}65 \text { a } 74 \\
\text { anos }\end{array}$ & 169 & 1,93 & 0,05 & 2,3 & 0,00 & 0,0 & 0,09 & 4,1 & 0,14 & 6,3 & 2,21 & 1,20 & 3,22 \\
\hline
\end{tabular}

\subsection{Necessidades de Tratamento para Cárie Dentária}

As Tabelas 6 e 7 mostram os resultados para necessidade de tratamento expressos em médias (Tabela 6) e percentuais (Tabela 7). Em todas as idades o percentual de dentes com necessidade de algum tratamento de cárie é baixo. A necessidade mais frequente é de restaurações de uma superfície. 0 grupo de 65 a 74 anos, além de apresentar o maior componente de perdidos no CPO-D, apresenta também o mais alto percentual de dentes com necessidade de exodontia.

Tabela 6. Médias das necessidades de tratamento para cárie dentária, segundo grupo etário. Anápolis-GO, 2010.

\begin{tabular}{|c|c|c|c|c|c|c|c|c|c|c|}
\hline \multirow[b]{2}{*}{ Grupo Etário } & \multirow[b]{2}{*}{$\mathrm{n}$} & \multirow[b]{2}{*}{$\begin{array}{l}\text { Dentes sem } \\
\text { necessidade }\end{array}$} & \multicolumn{8}{|c|}{ Dentes com necessidade } \\
\hline & & & $\begin{array}{c}\text { Rest. } 1 \\
\text { superfície }\end{array}$ & $\begin{array}{l}\text { Rest. } 2 \text { ou } \\
\text { mais } \\
\text { superfícies }\end{array}$ & $\begin{array}{l}\text { Coroa } \\
\text { por } \\
\text { qualquer } \\
\text { razão }\end{array}$ & $\begin{array}{l}\text { Faceta } \\
\text { Estética }\end{array}$ & $\begin{array}{l}\text { Trat. Pulpar } \\
\text { mais } \\
\text { restauração }\end{array}$ & Extração & $\begin{array}{l}\text { Remine- } \\
\text { ralização } \\
\text { de lesão } \\
\text { branca }\end{array}$ & Selante \\
\hline 5 anos & 176 & 18,32 & 1,23 & 0,67 & 0,00 & 0,00 & 0,13 & 0,02 & 0,00 & 0,05 \\
\hline 12 anos & 188 & 24,81 & 0,97 & 0,21 & 0,01 & 0,00 & 0,14 & 0,14 & 0,00 & 0,11 \\
\hline 15 a 19 anos & 151 & 26,19 & 0,92 & 0,20 & 0,01 & 0,00 & 0,22 & 0,12 & 0,01 & 0,30 \\
\hline 35 a 44 anos & 245 & 20,27 & 1,03 & 0,71 & 0,07 & 0,02 & 0,17 & 0,51 & 0,00 & 0,00 \\
\hline 65 a 74 anos & 169 & 4,00 & 0,29 & 0,12 & 0,01 & 0,01 & 0,01 & 0,15 & 0,00 & 0,00 \\
\hline
\end{tabular}


Tabela 7. Percentuais das necessidades de tratamento para cárie dentária, segundo grupo etário. Anápolis-GO, 2010.

\begin{tabular}{|c|c|c|c|c|c|c|c|c|c|c|}
\hline \multirow[b]{2}{*}{ Grupo Etário } & \multirow[b]{2}{*}{$\mathrm{n}$} & \multirow[b]{2}{*}{$\begin{array}{l}\text { Dentes sem } \\
\text { necessidade }\end{array}$} & \multicolumn{8}{|c|}{ Dentes com necessidade } \\
\hline & & & $\begin{array}{c}\text { Rest. } 1 \\
\text { superfície }\end{array}$ & $\begin{array}{l}\text { Rest. } 2 \text { ou } \\
\text { mais } \\
\text { superfícies }\end{array}$ & $\begin{array}{l}\text { Coroa } \\
\text { por } \\
\text { qualquer } \\
\text { razão }\end{array}$ & $\begin{array}{l}\text { Faceta } \\
\text { Estética }\end{array}$ & $\begin{array}{l}\text { Trat. Pulpar } \\
\text { mais } \\
\text { restauração }\end{array}$ & Extração & $\begin{array}{c}\text { Remine- } \\
\text { ralização } \\
\text { de lesão } \\
\text { branca }\end{array}$ & Selante \\
\hline 5 anos & 176 & 89,72 & 6,02 & 3,28 & 0,00 & 0,00 & 0,64 & 0,10 & 0,00 & 0,24 \\
\hline 12 anos & 188 & 94,01 & 3,68 & 0,80 & 0,04 & 0,00 & 0,53 & 0,53 & 0,00 & 0,42 \\
\hline 15 a 19 anos & 151 & 93,64 & 3,29 & 0,72 & 0,04 & 0,00 & 0,79 & 0,43 & 0,04 & 1,07 \\
\hline 35 a 44 anos & 245 & 88,98 & 4,52 & 3,12 & 0,31 & 0,09 & 0,75 & 2,24 & 0,00 & 0,00 \\
\hline 65 a 74 anos & 169 & 87,15 & 6,32 & 2,61 & 0,22 & 0,22 & 0,22 & 3,27 & 0,00 & 0,00 \\
\hline
\end{tabular}

\subsection{Condição Periodontal}

As Tabelas 8 a 10 ilustram a condição periodontal, medida pelo CPI (Índice Periodontal Comunitário) e PIP (Índice de Perda de Inserção Periodontal).

O Índice CPI foi utilizado para identificar a presença de sangramento e de cálculo na idade de 12 anos e, sangramento, cálculo e bolsas periodontais rasas (de 3 a $5 \mathrm{~mm}$ ) e profundas ( $6 \mathrm{~mm}$ ou mais) nos grupos representativos dos adolescentes (15 a 19 anos), dos adultos (35 a 44 anos) e dos idosos. Nos adultos e idosos também se dimensionou a Perda de Inserção Periodontal pelo PIP.

As Tabelas 8 a 10 ilustram a condição periodontal, medida pelo CPI (Índice Periodontal Comunitário) e PIP (Índice de Perda de Inserção Periodontal). A condição periodontal mais observada é o cálculo. À medida que aumenta a idade, cresce a prevalência de bolsas periodontais, principalmente as rasas.

Com relação à perda de inserção periodontal, entre os adultos quase $60 \%$ apresentam nível de inserção normal, $10 \%$ têm perda de 4 a $5 \mathrm{~mm}$ e quase um terço apresentam sextantes excluídos. Em idosos, a perda de inserção é muito baixa, pelo fato da maioria dos sextantes $(93,5 \%)$ terem sido diagnosticados como excluídos, por terem sido extraídos.

Tabela 8. Percentual de indivíduos segundo Condição Periodontal medida pelo Índice Periodontal Comunitário (CPI) e grupo etário. Anápolis-GO, 2010.

\begin{tabular}{|c|c|c|c|c|c|c|c|c|c|c|c|c|c|c|c|c|}
\hline \multirow[b]{3}{*}{ Grupo Etário } & \multicolumn{4}{|c|}{12 anos } & \multicolumn{4}{|c|}{15 a 19 anos } & \multicolumn{4}{|c|}{35 a 44 anos } & \multicolumn{4}{|c|}{65 a 74 anos } \\
\hline & \multirow[b]{2}{*}{$\mathrm{N}$} & \multirow[b]{2}{*}{$\%$} & \multicolumn{2}{|c|}{ IC (95\%) } & \multirow[b]{2}{*}{$\mathrm{N}$} & \multirow[b]{2}{*}{$\%$} & \multicolumn{2}{|c|}{ IC (95\%) } & \multirow[b]{2}{*}{$\mathrm{N}$} & \multirow[b]{2}{*}{$\%$} & \multicolumn{2}{|c|}{ IC (95\%) } & \multirow[b]{2}{*}{$\mathrm{n}$} & \multirow[b]{2}{*}{$\%$} & \multicolumn{2}{|c|}{ IC $(95 \%)$} \\
\hline & & & L.I. & L.S. & & & L.I. & L.S. & & & L.I. & L.S. & & & L.I. & L.S. \\
\hline Hígido & 125 & 67,4 & 58,7 & 75,1 & 91 & 59,4 & 48,0 & 69,9 & 37 & 14,1 & 10,3 & 19,1 & 1 & 0,4 & 0,0 & 3,0 \\
\hline Sangramento & 12 & 5,0 & 2,3 & 10,2 & 9 & 4,0 & 1,7 & 9,1 & 3 & 1,0 & 0,3 & 3,4 & 0 & 0,0 & 0,0 & 0,0 \\
\hline Cálculo & 43 & 24,3 & 17,5 & 32,6 & 43 & 31,5 & 22,2 & 42,7 & 88 & 34,5 & 25,5 & 44,9 & 6 & 3,8 & 1,3 & 10,6 \\
\hline Bolsa 4-5 mm & - & - & - & - & 8 & 5,0 & 2,4 & 10,0 & 40 & 15,5 & 11,1 & 21,3 & 5 & 2,3 & 0,9 & 6,1 \\
\hline Bolsa $6 \mathrm{~mm}$ ou + & - & - & - & - & 0 & 0,0 & 0,0 & 0,0 & 10 & 4,8 & 2,1 & 10,7 & 0 & 0,0 & 0,0 & 0,0 \\
\hline Excluído & 7 & 3,3 & 0,9 & 12,0 & 0 & 0,0 & 0,0 & 0,0 & 66 & 30,0 & 23,8 & 37,0 & 157 & 93,5 & 87,0 & 96,9 \\
\hline
\end{tabular}


Tabela 9. Prevalência de Sangramento, Cálculo e Bolsa Periodontal Rasa e Profunda segundo grupo etário. Anápolis-GO, 2010.

\begin{tabular}{|c|c|c|c|c|c|c|c|c|c|c|c|c|c|c|c|c|}
\hline \multirow[b]{3}{*}{ Grupo Etário } & \multicolumn{4}{|c|}{12 anos } & \multicolumn{4}{|c|}{15 a 19 anos } & \multicolumn{4}{|c|}{35 a 44 anos } & \multicolumn{4}{|c|}{65 a 74 anos } \\
\hline & \multirow[b]{2}{*}{$\mathrm{N}$} & \multirow[b]{2}{*}{$\%$} & \multicolumn{2}{|c|}{ IC (95\%) } & \multirow[b]{2}{*}{$\mathrm{N}$} & \multirow[b]{2}{*}{$\%$} & \multicolumn{2}{|c|}{ IC (95\%) } & \multirow[b]{2}{*}{$\mathrm{N}$} & \multirow[b]{2}{*}{$\%$} & \multicolumn{2}{|c|}{ IC $(95 \%)$} & \multirow[b]{2}{*}{$\mathrm{n}$} & \multirow[b]{2}{*}{$\%$} & \multicolumn{2}{|c|}{ IC $(95 \%)$} \\
\hline & & & L.I. & L.S. & & & L.I. & L.S. & & & L.I. & L.S. & & & L.I. & L.S. \\
\hline Sangramento & 25 & 11,8 & 7,5 & 18,0 & 27 & 16,4 & 10,8 & 24,0 & 72 & 32,0 & 21,0 & 45,4 & 13 & 7,6 & 3,6 & 15,4 \\
\hline Cálculo & 47 & 26,2 & 19,1 & 34,9 & 48 & 34,7 & 24,3 & 46,8 & 182 & 75,9 & 69,0 & 81,6 & 47 & 25,2 & 17,9 & 34,3 \\
\hline Bolsa 4-5 mm & - & - & - & - & 8 & 5,0 & 2,4 & 10,0 & 73 & 29,5 & 18,7 & 43,2 & 23 & 11,4 & 6,6 & 19,2 \\
\hline Bolsa $6 \mathrm{~mm}$ ou + & - & - & - & - & 0 & 0,0 & 0,0 & 0,0 & 14 & 6,1 & 3,1 & 11,6 & 1 & 0,5 & 0,1 & 3,7 \\
\hline
\end{tabular}

Tabela 10. Índice de Perda de Inserção Periodontal (PIP) em percentuais de pior escore apresentado segundo grupo etário. Anápolis-GO, 2010.

\begin{tabular}{|c|c|c|c|c|c|c|c|c|}
\hline \multirow[b]{3}{*}{ PIP } & \multirow[b]{3}{*}{$\mathrm{n}$} & \multicolumn{3}{|c|}{35 a 44 anos } & \multirow[b]{3}{*}{$\mathrm{N}$} & \multicolumn{3}{|c|}{65 a 74 anos } \\
\hline & & \multirow[b]{2}{*}{$\%$} & \multicolumn{2}{|c|}{$\mathrm{IC}(95 \%)$} & & \multirow[b]{2}{*}{$\%$} & \multicolumn{2}{|c|}{$\mathrm{IC}(95 \%)$} \\
\hline & & & L.I. & L.S. & & & L.I. & L.S. \\
\hline Perda 0-3 mm & 148 & 57,8 & 49,0 & 66,1 & 10 & 5,9 & 2,8 & 12,1 \\
\hline Perda 4-5 mm & 27 & 10,3 & 6,9 & 15,1 & 1 & 0,3 & 0,0 & 2,4 \\
\hline Perda 6-8 mm & 3 & 1,5 & 0,4 & 5,2 & 1 & 0,3 & 0,0 & 2,4 \\
\hline Perda 9-11 mm & 1 & 0,7 & 0,1 & 5,0 & 0 & 0,0 & 0,0 & 0,0 \\
\hline Perda $12 \mathrm{~mm} \mathrm{e} \mathrm{+}$ & 1 & 0,4 & 0,1 & 3,2 & 0 & 0,0 & 0,0 & 0,0 \\
\hline Excluído & 64 & 29,3 & 22,9 & 36,6 & 157 & 93,5 & 87,0 & 96,9 \\
\hline
\end{tabular}

\subsection{Oclusão Dentária}

A Tabela 11 mostra a situação de oclusão dentária aos 5 anos, avaliada pelo índice de Foster e Hamilton. Na Tabela 1 encontra-se a situação de oclusão para a idade de 12 anos e para o grupo etário de 15 a 19 anos medida pelo DAI (Índice de Estética Dentária).

$\mathrm{Na}$ dentição decídua, quase $60 \%$ das crianças de 5 anos apresenta algum tipo de disfunção. $\mathrm{Na}$ dentição permanente, $58,2 \%$ das crianças de 12 anos não apresentam problemas oclusais, sendo este percentual de $52,6 \%$ em adolescentes de 15 a 19 anos. Chama a atenção o percentual de adolescentes $(11,7 \%)$ com oclusopatia muito severa. 
Tabela 11. Condição de oclusão dentária analisada pelo Índice de Estética Dentária (DAI). Anápolis-GO, 2010.

\begin{tabular}{|c|c|c|c|c|}
\hline \multirow[b]{2}{*}{ Chave de Caninos } & \multirow[b]{2}{*}{$\mathrm{N}$} & \multirow[b]{2}{*}{$\%$} & \multicolumn{2}{|c|}{ IC $(95 \%)$} \\
\hline & & & L.I. & L.S. \\
\hline Classe I & 135 & 80,0 & 72,0 & 86,1 \\
\hline Classe II & 20 & 11,4 & 7,2 & 17,6 \\
\hline Classe III & 18 & 8,7 & 4,2 & 17,2 \\
\hline \multicolumn{5}{|l|}{ Sobressaliência } \\
\hline Normal & 106 & 73,1 & 61,3 & 82,3 \\
\hline Aumentado & 27 & 17,9 & 10,9 & 28,0 \\
\hline Topo a topo & 10 & 7,7 & 3,5 & 15,9 \\
\hline Cruzada Anterior & 3 & 1,4 & 0,4 & 5,0 \\
\hline \multicolumn{5}{|l|}{ Sobremordida } \\
\hline Normal & 93 & 67,7 & 55,7 & 77,8 \\
\hline Reduzida & 16 & 11,2 & 6,4 & 18,8 \\
\hline Aberta & 11 & 7,0 & 4,2 & 11,4 \\
\hline Profunda & 26 & 14,1 & 7,7 & 24,4 \\
\hline \multicolumn{5}{|c|}{ Mordida Cruzada Posterior } \\
\hline Ausência & 158 & 91,6 & 85,0 & 95,4 \\
\hline Presença & 16 & 8,4 & 4,6 & 15,0 \\
\hline \multicolumn{5}{|c|}{ Presença de, pelo menos, uma condição anterior } \\
\hline Não & 64 & 41,6 & 30,9 & 53,1 \\
\hline Sim & 110 & 58,4 & 46,9 & 69,1 \\
\hline
\end{tabular}

Tabela 12. Condição de oclusão dentária analisada pelo Índice de Estética Dentária (DAI), segundo grupo etário. Anápolis-GO, 2010.

\begin{tabular}{|c|c|c|c|c|c|c|c|c|}
\hline \multirow[b]{3}{*}{ Classe DAÍ } & \multicolumn{4}{|c|}{12 anos } & \multicolumn{4}{|c|}{15 a 19 anos } \\
\hline & \multirow[b]{2}{*}{$\mathrm{n}$} & \multirow[b]{2}{*}{$\%$} & \multicolumn{2}{|c|}{ IC(95\%) } & \multirow[b]{2}{*}{$\mathrm{n}$} & \multirow[b]{2}{*}{$\%$} & \multicolumn{2}{|c|}{ IC(95\%) } \\
\hline & & & L.I. & L.S. & & & L.I. & L.S. \\
\hline Sem Oclusopatia & 111 & 58,2 & 50,7 & 65,4 & 71 & 52,6 & 42,7 & 62,3 \\
\hline Oclusopatia Definida & 39 & 21,6 & 15,3 & 29,8 & 36 & 28,8 & 19,3 & 40,7 \\
\hline Oclusopatia Severa & 24 & 13,8 & 8,0 & 22,7 & 14 & 6,9 & 3,0 & 15,1 \\
\hline Oclusopatia Muito Severa & 12 & 6,4 & 3,3 & 11,8 & 17 & 11,7 & 7,4 & 18,0 \\
\hline
\end{tabular}

\subsection{Uso e Necessidade de Prótese}

As Tabelas 13 a 15 mostram a situação de edentulismo. Nas Tabelas 13 e 14 podem ser visualizados os resultados para uso de prótese (superior e inferior) e na Tabela 15, os resultados para a necessidade de prótese.

O uso de prótese é bastante baixo em adolescentes de 15 a 19 anos $(6,9 \%)$, porém corresponde a $37,1 \%$ nos adultos e quase $80 \%$ em idosos. A maior prevalência de uso é de prótese removível em adultos e de prótese total em idosos. 
Com relação à necessidade, $76,2 \%$ dos adultos necessita de algum tipo de prótese, sendo a parcial em dois maxilares o tipo mais frequente. Em idosos, 70,4\% necessitam de prótese e a maior necessidade é de prótese total nos dois maxilares.

Tabela 13. Uso de Prótese Dentária Superior segundo o tipo de prótese e grupo etário. Anápolis-GO, 2010.

\begin{tabular}{|c|c|c|c|c|c|c|c|c|c|c|c|c|c|c|c|c|c|c|c|}
\hline \multirow[b]{4}{*}{ Grupo Etário } & \multirow[b]{4}{*}{$\mathrm{N}$} & \multirow{2}{*}{\multicolumn{3}{|c|}{ Não Usa }} & \multicolumn{15}{|c|}{ Uso de Prótese Superior } \\
\hline & & & & & \multicolumn{3}{|c|}{ Uma Ponte Fixa } & \multicolumn{3}{|c|}{ Mais de $1 \mathrm{PF}$} & \multicolumn{3}{|c|}{$\begin{array}{l}\text { Prótese Parcial } \\
\text { Removível }\end{array}$} & \multicolumn{3}{|c|}{$\begin{array}{c}\text { Prótese Fixa + } \\
\text { Removível }\end{array}$} & \multicolumn{3}{|c|}{ Prótese Total } \\
\hline & & \multirow[b]{2}{*}{$\%$} & \multicolumn{2}{|c|}{$\mathrm{IC}(95 \%)$} & \multirow[b]{2}{*}{$\%$} & \multicolumn{2}{|c|}{ IC(95\%) } & \multirow[b]{2}{*}{$\%$} & \multicolumn{2}{|c|}{$\mathrm{IC}(95 \%)$} & \multirow[b]{2}{*}{$\%$} & \multicolumn{2}{|c|}{ IC(95\%) } & \multirow[b]{2}{*}{$\%$} & \multicolumn{2}{|c|}{$\mathrm{IC}(95 \%)$} & \multirow[b]{2}{*}{$\%$} & \multicolumn{2}{|c|}{$\mathrm{IC}(95 \%)$} \\
\hline & & & L.I. & L.S. & & L.I. & L.S. & & L.I. & L.S. & & L.I. & L.S. & & L.I. & L.S. & & L.I. & L.S. \\
\hline 15 a 19 anos & 151 & 93,1 & 88,2 & 96,0 & 5,7 & 2,8 & 11,0 & 0,0 & 0,0 & 0,0 & 0,6 & 0,1 & 4,4 & 0,7 & 0,1 & 5,0 & 0,0 & 0,0 & 0,0 \\
\hline 35 a 44 anos & 244 & 62,9 & 53,2 & 71,7 & 1,1 & 0,2 & 5,5 & 0,5 & 0,1 & 2,3 & 24,6 & 19,1 & 31,1 & 1,5 & 0,4 & 5,2 & 9,4 & 5,7 & 15,1 \\
\hline 65 a 74 anos & 169 & 21,1 & 14,3 & 30,0 & 0,5 & 0,1 & 3,6 & 1,5 & 0,3 & 6,5 & 5,2 & 2,4 & 10,6 & 0,4 & 0,0 & 3,0 & 71,3 & 62,1 & 79,1 \\
\hline
\end{tabular}

Tabela 14. Uso de Prótese Dentária Inferior segundo o tipo de prótese e grupo etário. Anápolis-GO, 2010.

\begin{tabular}{|c|c|c|c|c|c|c|c|c|c|c|c|c|c|c|c|c|c|c|c|}
\hline \multirow[b]{4}{*}{ Grupo Etário } & \multirow[b]{4}{*}{$\mathrm{N}$} & \multirow{2}{*}{\multicolumn{3}{|c|}{ Não Usa }} & \multicolumn{15}{|c|}{ Uso de Prótese Inferior } \\
\hline & & & & & \multicolumn{3}{|c|}{ Uma Ponte Fixa } & \multicolumn{3}{|c|}{ Mais de $1 \mathrm{PF}$} & \multicolumn{3}{|c|}{$\begin{array}{l}\text { Prótese Parcial } \\
\text { Removível }\end{array}$} & \multicolumn{3}{|c|}{$\begin{array}{c}\text { Prótese Fixa + } \\
\text { Removível }\end{array}$} & \multicolumn{3}{|c|}{ Prótese Total } \\
\hline & & \multirow[b]{2}{*}{$\%$} & \multicolumn{2}{|c|}{$\mathrm{IC}(95 \%)$} & \multirow[b]{2}{*}{$\%$} & \multicolumn{2}{|c|}{$\mathrm{IC}(95 \%)$} & \multirow[b]{2}{*}{$\%$} & \multicolumn{2}{|c|}{ IC(95\%) } & \multirow[b]{2}{*}{$\%$} & \multicolumn{2}{|c|}{$\operatorname{IC}(95 \%)$} & \multirow[b]{2}{*}{$\%$} & \multicolumn{2}{|c|}{$\mathrm{IC}(95 \%)$} & \multirow[b]{2}{*}{$\%$} & \multicolumn{2}{|c|}{ IC(95\%) } \\
\hline & & & L.I. & L.S. & & L.I. & L.S. & & L.I. & L.S. & & L.I. & L.S. & & L.I. & L.S. & & L.I. & L.S. \\
\hline 15 a 19 anos & 151 & 100,0 & 100,0 & 100,0 & 0,0 & 0,0 & 0,0 & 0,0 & 0,0 & 0,0 & 0,0 & 0,0 & 0,0 & 0,0 & 0,0 & 0,0 & 0,0 & 0,0 & 0,0 \\
\hline 35 a 44 anos & 244 & 87,3 & 79,8 & 92,2 & 1,6 & 0,4 & 5,8 & 0,0 & 0,0 & 0,0 & 7,8 & 4,8 & 12,6 & 1,0 & 0,2 & 6,0 & 2,3 & 0,8 & 6,1 \\
\hline 65 a 74 anos & 169 & 43,8 & 33,9 & 54,2 & 1,1 & 0,3 & 3,8 & 0,3 & 0,0 & 2,4 & 14,4 & 9,8 & 20,6 & 1,0 & 0,2 & 4,6 & 39,3 & 30,7 & 48,6 \\
\hline
\end{tabular}

Tabela 15. Necessidade de Prótese Dentária segundo o tipo de prótese e grupo etário. Anápolis-GO, 2010.

\begin{tabular}{|c|c|c|c|c|c|c|c|c|c|c|c|c|c|c|c|c|c|c|c|}
\hline \multirow[b]{4}{*}{ Grupo Etário } & \multirow[b]{4}{*}{$\mathrm{N}$} & \multirow{2}{*}{\multicolumn{3}{|c|}{ Não Necessita }} & \multicolumn{15}{|c|}{ Necessidade de Prótese } \\
\hline & & & & & \multicolumn{3}{|c|}{ Parcial 1 maxilar } & \multicolumn{3}{|c|}{ Parcial 2 maxilares } & \multicolumn{3}{|c|}{ Total 1 maxilar } & \multicolumn{3}{|c|}{ Parcial + Total } & \multicolumn{3}{|c|}{ Total 2 maxilares } \\
\hline & & \multirow[b]{2}{*}{$\%$} & \multicolumn{2}{|c|}{ IC(95\%) } & \multirow[b]{2}{*}{$\%$} & \multicolumn{2}{|c|}{ IC(95\%) } & \multirow[b]{2}{*}{$\%$} & \multicolumn{2}{|c|}{ IC(95\%) } & \multirow[b]{2}{*}{$\%$} & \multicolumn{2}{|c|}{$\mathrm{IC}(95 \%)$} & \multirow[b]{2}{*}{$\%$} & \multicolumn{2}{|c|}{ IC(95\%) } & \multirow[b]{2}{*}{$\%$} & \multicolumn{2}{|c|}{ IC(95\%) } \\
\hline & & & L.I. & L.S. & & L.I. & L.S. & & L.I. & L.S. & & L.I. & L.S. & & L.I. & L.S. & & L.I. & L.S. \\
\hline 15 a 19 anos & 151 & 90,9 & 85,2 & 94,6 & 6,4 & 3,6 & 10,9 & 2,7 & 1,1 & 6,8 & 0,0 & 0,0 & 0,0 & 0,0 & 0,0 & 0,0 & 0,0 & 0,0 & 0,0 \\
\hline 35 a 44 anos & 244 & 23,8 & 16,2 & 33,6 & 28,7 & 21,0 & 37,9 & 41,1 & 30,4 & 52,7 & 0,3 & 0,0 & 2,3 & 4,4 & 2,0 & 9,3 & 1,7 & 0,5 & 5,2 \\
\hline 65 a 74 anos & 169 & 29,6 & 21,4 & 39,4 & 7,0 & 4,0 & 12,0 & 9,0 & 4,8 & 16,1 & 8,1 & 5,4 & 12,1 & 13,0 & 7,2 & 22,3 & 33,2 & 25,3 & 42,2 \\
\hline
\end{tabular}

\subsection{Traumatismo Dentário}

As Tabelas 16 e 17 mostram, respectivamente, a prevalência e o número médio de dentes afetados pelo traumatismo dentário em crianças de 12 anos. Em Anápolis, um quarto da amostra apresentou traumatismo dentário em pelo menos um dente incisivo. $O$ tipo de lesão mais 
frequente foi fratura de esmalte $(22,7 \%)$ seguida pela fratura de esmalte e dentina $(2,2 \%)$. Nesse estudo epidemiológico, nenhum caso de fratura com exposição pulpar ou ausência devida a trauma foi identificado.

Tabela 16. Prevalência de pelo menos um dente incisivo afetado por traumatismo em crianças de 12 anos. Anápolis-GO, 2010.

\begin{tabular}{lrrrr}
\hline \hline & & & \multicolumn{2}{c}{ IC (95\%) } \\
\cline { 5 - 6 } & $\mathrm{n}$ & \multicolumn{1}{c}{$\%$} & L.I. & L.S. \\
\hline \hline Nenhum Traumatismo & 139 & $\mathbf{7 5 , 1}$ & 61,3 & 80,3 \\
Fratura de Esmalte & 42 & $\mathbf{2 2 , 7}$ & 16,9 & 32,7 \\
Fratura de Esmalte e Dentina & 4 & $\mathbf{2 , 2}$ & 1,3 & 13,3 \\
Fratura com Exposição Pulpar & 0 & $\mathbf{0 , 0}$ & 0,0 & 0,0 \\
Ausência devida a trauma & 0 & $\mathbf{0 , 0}$ & 0,0 & 0,0 \\
\hline \hline
\end{tabular}

Tabela 17. Média de dentes incisivos afetados por traumatismo em crianças de 12 anos. Anápolis. 2010.

\begin{tabular}{lrrrr}
\hline \hline & & & \multicolumn{2}{c}{ IC $(95 \%)$} \\
\cline { 4 - 5 } & $\mathrm{n}$ & Média & L.I. & L.S. \\
\hline \hline Nenhum Traumatismo & 139 & $\mathbf{1 , 5 2}$ & 0,46 & 0,63 \\
Fratura de Esmalte & 42 & $\mathbf{0 , 0 6}$ & 0,01 & 0,03 \\
Fratura de Esmalte e Dentina & 4 & $\mathbf{0 , 0 1}$ & 0.00 & 0,01 \\
Fratura com Exposição Pulpar & 0 & $\mathbf{0 , 0 0}$ & 0,00 & 0,00 \\
Ausência devida a trauma & 0 & $\mathbf{0 , 0 0}$ & 0,00 & 0,00 \\
\hline \hline
\end{tabular}

\subsection{Fluorose Dentária}

A Tabela 18 mostra os resultados para fluorose dentária em crianças de 12 anos. A maioria dos examinados não apresentaram fluorose $(81,2 \%)$. Não foram identificados indivíduos com fluorose grave.

Tabela 18. Prevalência e gravidade da fluorose dentária aos 12 anos. Anápolis-GO, 2010.

\begin{tabular}{lcccc}
\hline \hline & & & \multicolumn{2}{c}{ IC (95\%) } \\
\cline { 5 - 6 } & $\mathrm{n}$ & $\%$ & L.I. & L.S. \\
\hline \hline Sem Fluorose & 150 & $\mathbf{8 1 , 2}$ & 58,5 & 88,8 \\
\hline Normal & 126 & $\mathbf{6 8 , 3}$ & 58,5 & 78,4 \\
Questionável & 24 & $\mathbf{1 2 , 9}$ & 7,60 & 20,4 \\
\hline Com Fluorose & 35 & $\mathbf{1 8 , 8}$ & 11,2 & 27,6 \\
\hline Muito Leve & 21 & $\mathbf{1 1 , 3}$ & 5,8 & 20,0 \\
Leve & 10 & $\mathbf{5 , 4}$ & 2,6 & 8,7 \\
Moderada & 4 & $\mathbf{2 , 1}$ & 0,7 & 6,3 \\
Grave & 0 & $\mathbf{0 , 0}$ & 0,0 & 0,0 \\
\hline \hline
\end{tabular}




\subsection{Morbidade dentária referida, uso de serviços odontológicos e impactos da saúde bucal na vida diária}

A Tabela 19 mostra os resultados da morbidade dentária referida e da prevalência e gravidade da dor de origem dentária. Na Tabela 20 estão os resultados para o uso de serviços odontológicos. Na Tabela 21, a percepção de saúde bucal e os impactos da saúde bucal na vida diária, medidos pelo OIDP (Oral Impact on Daily Living).

A prevalência de dor de dente afeta mais as crianças e os adultos, e tende a diminuir entre os idosos.

A maioria das crianças e os adolescentes consultou dentista nos últimos 12 meses, já os adultos e os idosos a frequência é de 3 ou mais anos.

O uso de serviço odontológico do setor público foi apontado aos 12 anos como o mais utilizado $(61,6 \%)$. Entretanto para os demais grupos etários o serviço particular em Anápolis foi o mais citado em mais da metade dos entrevistados.

Observa-se que em mais da metade dos entrevistados se mostraram muito satisfeitos ou satisfeitos com os dentes e com a boca, exceto no grupo dos adultos em que o maior percentual $(43,9 \%)$ se declararam insatisfeitos ou muito insatisfeitos.

Quanto a avaliação do impacto das condições de saúde bucal sobre a vida diária, os adolescentes citaram que o estado emocional foi a característica mais afetada pelas condições bucais. Para os adultos o impacto maior estava no sorriso e na alimentação. Os idosos também apontaram a alimentação e a fala como dimensões mais afetadas pela condição de saúde bucal na vida diária. Percebe-se que a dificuldade em comer aumenta consideravelmente com a idade.

Tabela 19. Morbidade dentária auto-referida, prevalência e gravidade da dor de dente segundo grupo etário. Anápolis-GO, 2010.

\begin{tabular}{|c|c|c|c|c|c|c|c|c|c|c|c|c|c|}
\hline & \multirow[b]{4}{*}{$\mathrm{n}$} & \multicolumn{12}{|c|}{ Grupo Etário } \\
\hline & & \multicolumn{3}{|c|}{12 anos } & \multicolumn{3}{|c|}{15 a 19 anos } & \multicolumn{3}{|c|}{35 a 44 anos } & \multicolumn{3}{|c|}{65 a 74 anos } \\
\hline & & \multirow[b]{2}{*}{$\%$} & \multicolumn{2}{|c|}{ IC $(95 \%)$} & \multirow[b]{2}{*}{$\%$} & \multicolumn{2}{|c|}{ IC $(95 \%)$} & \multirow[b]{2}{*}{$\%$} & \multicolumn{2}{|c|}{ IC $(95 \%)$} & \multirow[b]{2}{*}{$\%$} & \multicolumn{2}{|c|}{ IC $(95 \%)$} \\
\hline & & & L.I. & L.S. & & L.I. & L.S. & & L.I. & L.S. & & L.I. & L.S. \\
\hline \multicolumn{14}{|l|}{ Morbidade Dentária } \\
\hline Não & 257 & 30,6 & 22,3 & 40,5 & 35,6 & 26,5 & 45,9 & 17,9 & 13,5 & 23,2 & 57,2 & 46,8 & 67,1 \\
\hline Sim & 476 & 64,5 & 54,2 & 73,7 & 56,2 & 43,0 & 68,6 & 80,8 & 75,4 & 85,3 & 41,8 & 32,1 & 52,2 \\
\hline Não Sabe / Não Respondeu & 20 & 4,8 & 2,1 & 10,7 & 8,2 & 2,5 & 23,8 & 1,3 & 0,3 & 5,3 & 1,0 & 0,2 & 4,0 \\
\hline \multicolumn{14}{|l|}{ Dor de Dente (6 meses) } \\
\hline Não & 549 & 63,5 & 55,1 & 71,2 & 76,5 & 64,9 & 85,1 & 72,1 & 64,0 & 79,0 & 91,1 & 83,0 & 95,6 \\
\hline Sim & 199 & 36,5 & 28,8 & 44,9 & 23,5 & 14,9 & 35,1 & 27,9 & 21,0 & 36,0 & 8,4 & 4,1 & 16,7 \\
\hline Não Sabe / Não Respondeu & 1 & 0,0 & 0,0 & 0,0 & 0,0 & 0,0 & 0,0 & 0,0 & 0,0 & 0,0 & 0,4 & 0,1 & 3,3 \\
\hline \multicolumn{14}{|l|}{ Gravidade da Dor de Dente } \\
\hline Grau 1 & 32 & 15,2 & 6,8 & 30,5 & 16,7 & 6,5 & 36,6 & 18,1 & 11,9 & 26,5 & 20,3 & 7,2 & 45,7 \\
\hline Grau 2 & 40 & 24,8 & 11,0 & 46,8 & 19,4 & 9,4 & 35,8 & 16,6 & 8,8 & 29,2 & 22,5 & 4,7 & 63,0 \\
\hline Grau 3 & 54 & 35,9 & 26,4 & 46,5 & 29,6 & 18,0 & 44,7 & 10,9 & 5,0 & 22,0 & 30,4 & 9,6 & 64,2 \\
\hline Grau 4 & 33 & 13,2 & 6,8 & 23,8 & 15,2 & 5,6 & 35,3 & 20,6 & 10,8 & 35,7 & 11,2 & 2,9 & 34,5 \\
\hline Grau 5 & 40 & 11,0 & 4,9 & 22,9 & 19,1 & 7,5 & 40,7 & 33,8 & 19,5 & 51,9 & 15,6 & 4,9 & 39,6 \\
\hline
\end{tabular}


Tabela 20. Uso de serviços odontológicos segundo grupo etário. Anápolis-GO, 2010.

\begin{tabular}{|c|c|c|c|c|c|c|c|c|c|c|c|c|c|}
\hline & \multirow[b]{4}{*}{$\mathrm{n}$} & \multicolumn{12}{|c|}{ Grupo Etário } \\
\hline & & \multicolumn{3}{|c|}{12 anos } & \multicolumn{3}{|c|}{15 a 19 anos } & \multicolumn{3}{|c|}{35 a 44 anos } & \multicolumn{3}{|c|}{65 a 74 anos } \\
\hline & & \multirow[b]{2}{*}{$\%$} & \multicolumn{2}{|c|}{ IC $(95 \%)$} & \multirow[b]{2}{*}{$\%$} & \multicolumn{2}{|c|}{ IC $(95 \%)$} & \multirow[b]{2}{*}{$\%$} & \multicolumn{2}{|c|}{ IC $(95 \%)$} & \multirow[b]{2}{*}{$\%$} & \multicolumn{2}{|c|}{ IC $(95 \%)$} \\
\hline & & & L.I. & L.S. & & L.I. & L.S. & & L.I. & L.S. & & L.I. & L.S. \\
\hline \multicolumn{14}{|l|}{ Consulta ao dentista } \\
\hline Não & 16 & 8,0 & 5,1 & 12,3 & 7,1 & 4,1 & 12,1 & 3,2 & 1,1 & 8,7 & 6,5 & 1,8 & 21,0 \\
\hline Sim & 172 & 92,0 & 87,7 & 94,9 & 92,9 & 87,9 & 95,9 & 96,5 & 90,8 & 98,7 & 93,0 & 79,0 & 97,9 \\
\hline Não Sabe / Não Respondeu & 0 & 0,0 & 0,0 & 0,0 & 0,0 & 0,0 & 0,0 & 0,4 & 0,0 & 2,7 & 0,4 & 0,1 & 3,3 \\
\hline \multicolumn{14}{|l|}{ Frequência de consulta } \\
\hline Menos de 1 ano & 92 & 50,6 & 40,7 & 60,5 & 55,0 & 47,1 & 62,5 & 35,7 & 22,7 & 51,1 & 26,5 & 19,6 & 34,7 \\
\hline 1 a 2 anos & 59 & 37,0 & 29,8 & 44,9 & 32,3 & 25,0 & 40,7 & 25,5 & 18,0 & 34,7 & 16,8 & 11,5 & 23,8 \\
\hline 3 ou mais anos & 17 & 10,7 & 6,2 & 17,7 & 12,2 & 6,1 & 23,0 & 38,9 & 25,7 & 53,9 & 53,2 & 45,1 & 61,1 \\
\hline Não sabe/Não respondeu & 4 & 1,7 & 0,5 & 5,7 & 0,5 & 0,1 & 4,1 & 0,0 & 0,0 & 0,0 & 3,6 & 1,1 & 10,8 \\
\hline \multicolumn{14}{|l|}{ Onde consultou } \\
\hline Serviço Público & 99 & 61,6 & 48,1 & 73,5 & 42,4 & 28,0 & 58,1 & 41,7 & 33,0 & 51,0 & 25,7 & 20,4 & 31,7 \\
\hline Serviço Particular & 61 & 30,8 & 19,0 & 45,8 & 50,1 & 37,0 & 63,2 & 50,6 & 42,3 & 58,8 & 65,6 & 57,0 & 73,4 \\
\hline Plano de Saúde/Convênios & 5 & 3,3 & 1,2 & 8,7 & 7,5 & 2,8 & 18,7 & 6,0 & 3,7 & 9,6 & 4,6 & 2,2 & 9,3 \\
\hline Outros & 6 & 3,7 & 1,5 & 9,0 & 0,0 & 0,0 & 0,0 & 1,7 & 0,7 & 4,3 & 3,1 & 1,1 & 8,5 \\
\hline Não sabe/Não respondeu & 1 & 0,6 & 0,1 & 4,6 & 0,0 & 0,0 & 0,0 & 0,0 & 0,0 & 0,0 & 1,0 & 0,2 & 4,3 \\
\hline \multicolumn{14}{|l|}{ Motivo da última consulta } \\
\hline Revisão, prevenção ou check-up & 47 & 29,0 & 20,1 & 39,9 & 27,2 & 19,5 & 36,6 & 7,9 & 4,5 & 13,5 & 8,7 & 5,0 & 14,6 \\
\hline Dor & 39 & 22,2 & 15,2 & 31,4 & 18,7 & 13,3 & 25,7 & 21,5 & 15,9 & 28,5 & 6,4 & 2,5 & 15,6 \\
\hline Extração & 16 & 8,5 & 4,8 & 14,6 & 9,3 & 3,1 & 25,0 & 12,8 & 9,2 & 17,5 & 17,0 & 10,7 & 25,7 \\
\hline Tratamento & 68 & 38,8 & 32,1 & 46,1 & 37,2 & 28,1 & 47,3 & 55,4 & 49,1 & 61,6 & 52,9 & 42,4 & 63,2 \\
\hline Outros & 2 & 1,4 & 0,3 & 5,9 & 7,6 & 3,9 & 14,3 & 1,3 & 0,3 & 5,0 & 14,5 & 7,3 & 26,7 \\
\hline Não sabe/Não respondeu & 0 & 0,0 & 0,0 & 0,0 & 0,0 & 0,0 & 0,0 & 1,1 & 0,2 & 6,1 & 0,5 & 0,1 & 4,2 \\
\hline \multicolumn{14}{|l|}{ Avaliação da última consulta } \\
\hline Muito Bom & 50 & 27,2 & 18,9 & 37,4 & 34,4 & 19,3 & 53,6 & 29,4 & 19,2 & 42,2 & 33,4 & 19,6 & 50,9 \\
\hline Bom & 93 & 53,1 & 44,1 & 61,9 & 55,6 & 39,3 & 70,9 & 58,1 & 44,5 & 70,5 & 50,8 & 32,7 & 68,8 \\
\hline Regular & 20 & 13,4 & 7,9 & 21,9 & 8,1 & 4,6 & 13,9 & 6,6 & 3,5 & 12,0 & 9,0 & 5,1 & 15,3 \\
\hline Ruim & 6 & 4,9 & 2,4 & 9,7 & 1,3 & 0,3 & 5,6 & 3,4 & 1,8 & 6,1 & 2,8 & 1,1 & 6,9 \\
\hline Muito Ruim & 2 & 0,8 & 0,1 & 6,1 & 0,5 & 0,1 & 4,1 & 2,5 & 1,2 & 5,3 & 2,2 & 0,8 & 5,9 \\
\hline Não sabe/Não respondeu & 1 & 0,6 & 0,1 & 4,6 & 0,0 & 0,0 & 0,0 & 0,0 & 0,0 & 0,0 & 1,7 & 0,5 & 5,5 \\
\hline
\end{tabular}


Tabela 21. Percepção de saúde bucal e avaliação do impacto das condições de saúde bucal sobre a vida diária (OIDP) segundo as dimensões do índice e grupo etário. Anápolis-GO, 2010.

\begin{tabular}{|c|c|c|c|c|c|c|c|c|c|c|c|c|c|}
\hline & \multirow[b]{4}{*}{$\mathrm{n}$} & \multicolumn{12}{|c|}{ Grupo Etário } \\
\hline & & \multicolumn{3}{|c|}{12 anos } & \multicolumn{3}{|c|}{15 a 19 anos } & \multicolumn{3}{|c|}{35 a 44 anos } & \multicolumn{3}{|c|}{65 a 74 anos } \\
\hline & & \multirow[b]{2}{*}{$\%$} & \multicolumn{2}{|c|}{ IC $(95 \%)$} & \multirow[b]{2}{*}{$\%$} & \multicolumn{2}{|c|}{ IC $(95 \%)$} & \multirow[b]{2}{*}{$\%$} & \multicolumn{2}{|c|}{ IC $(95 \%)$} & \multirow[b]{2}{*}{$\%$} & \multicolumn{2}{|c|}{ IC $(95 \%)$} \\
\hline & & & L.I. & L.S. & & L.I. & L.S. & & L.I. & L.S. & & L.I. & L.S. \\
\hline \multicolumn{14}{|l|}{$\begin{array}{l}\text { Satisfação com dentes e } \\
\text { boca }\end{array}$} \\
\hline Muito Satisfeito & 93 & 11,2 & 5,9 & 20,1 & 13,7 & 7,1 & 24,6 & 10,4 & 4,9 & 20,7 & 13,8 & 5,8 & 29,4 \\
\hline Satisfeito & 287 & 51,7 & 42,3 & 61,0 & 38,3 & 29,6 & 47,8 & 29,5 & 21,6 & 38,9 & 43,0 & 30,4 & 56,6 \\
\hline Nem satisfeito nem insatisfeito & 152 & 16,9 & 12,3 & 22,8 & 31,0 & 24,0 & 39,1 & 16,2 & 11,4 & 22,4 & 16,8 & 10,4 & 26,0 \\
\hline Insatisfeito & 192 & 18,8 & 13,1 & 26,3 & 16,2 & 11,2 & 22,7 & 34,3 & 28,8 & 40,2 & 25,0 & 18,8 & 32,4 \\
\hline Muito Insatisfeito & 26 & 1,4 & 0,4 & 4,6 & 0,8 & 0,2 & 4,0 & 9,6 & 4,8 & 18,1 & 0,0 & 0,0 & 0,0 \\
\hline Não sabe/não respondeu & 3 & 0,0 & 0,0 & 0,0 & 0,0 & 0,0 & 0,0 & 0,0 & 0,0 & 0,0 & 1,4 & 0,4 & 4,6 \\
\hline \multicolumn{14}{|l|}{ Dimensões do OIDP } \\
\hline Comer & 184 & 15,7 & 10,0 & 24,0 & 13,3 & 8,4 & 20,6 & 33,8 & 29,3 & 38,6 & 31,3 & 25,3 & 38,0 \\
\hline Escovar os dentes & 139 & 18,4 & 13,4 & 24,8 & 9,8 & 6,5 & 14,6 & 30,9 & 24,3 & 38,4 & 10,2 & 6,0 & 16,7 \\
\hline Estado Emocional & 163 & 23,3 & 17,3 & 30,7 & 21,0 & 12,8 & 32,5 & 25,1 & 21,0 & 29,8 & 19,5 & 12,5 & 29,1 \\
\hline Contexto Social & 75 & 7,9 & 3,0 & 19,1 & 6,4 & 3,2 & 12,7 & 15,5 & 10,7 & 22,0 & 8,5 & 4,8 & 14,5 \\
\hline Prática de Esportes & 48 & 5,6 & 2,2 & 13,8 & 3,7 & 1,6 & 8,2 & 11,3 & 7,8 & 16,2 & 2,9 & 1,1 & 7,3 \\
\hline Falar & 71 & 6,2 & 3,5 & 10,9 & 1,7 & 0,5 & 5,7 & 11,4 & 7,1 & 17,9 & 23,1 & 14,2 & 35,4 \\
\hline Sorrir & 173 & 17,0 & 10,9 & 25,5 & 18,1 & 12,3 & 25,8 & 37,4 & 29,3 & 46,2 & 21,1 & 13,2 & 31,9 \\
\hline Estudar ou trabalhar & 63 & 7,9 & 4,7 & 13,0 & 4,8 & 2,2 & 10,0 & 16,1 & 8,7 & 27,7 & 2,2 & 0,9 & 5,6 \\
\hline Dormir & 94 & 11,8 & 6,9 & 19,3 & 8,8 & 3,6 & 19,9 & 17,3 & 11,2 & 25,7 & 11,2 & 5,6 & 21,2 \\
\hline OIDP total* & 374 & 44,7 & 37,9 & 51,6 & 40,2 & 31,8 & 49,1 & 60,1 & 56,0 & 64,1 & 47,6 & 40,7 & 54,7 \\
\hline
\end{tabular}

*OIDP total expressa a prevalência de, pelo menos, uma das situações anteriores.

\section{Considerações Finais}

A Pesquisa Nacional de Saúde Bucal - 2010, conhecida como Projeto SBBrasil 2010, analisou a situação da população brasileira com relação à cárie dentária, às doenças da gengiva, necessidades de próteses dentais, condições da oclusão, fluorose, traumatismo dentário e ocorrência de dor de dente, dentre outros aspectos, com o objetivo de proporcionar ao Ministério da Saúde e instituições do Sistema Único de Saúde (SUS), informações úteis que pudessem subsidiar o planejamento de programas de prevenção e tratamento no setor, tanto em nível nacional quanto no âmbito municipal.

O Projeto SBBrasil 2010 integra as ações de Vigilância em Saúde desenvolvidas pelo Ministério da Saúde e se constitui em peça-chave da Política Nacional de Saúde Bucal - Programa Brasil Sorridente, na medida em que seus resultados possibilitam avaliar o impacto de programas, identificar problemas e a partir desse conhecimento reorientar as estratégias de prevenção e assistência, especialmente as relacionadas com a implementação da Estratégia Saúde da Família (direcionada para a atenção básica) e dos Centros de Especialidades Odontológicas (CEO), elemento estruturante da atenção secundária em saúde bucal.

O presente levantamento constitui o primeiro levantamento de saúde bucal de Anápolis-GO com dados representativos para o município. A inexistência de estudos anteriores impossibilita a comparação com os dados aqui apresentados. 
Dentre os principais resultados apresentados ao longo deste relatório, destacam-se os relativos à cárie dentária, usualmente avaliada a partir do índice CPO. Devido ao seu caráter cumulativo ao longo dos anos, o CPO é sempre referido em relação à idade. Na idade de 12 anos é um indicador utilizado internacionalmente, pois reflete o ataque de cárie logo no começo da dentição permanente.

Aos 5 anos de idade o ceo-d configurou uma média de 2,5 dentes afetados, valor próximo da média nacional em 2010 (2,43). Observa-se que para essas crianças o maior problema são as cáries não tratadas, que pode sugerir dificuldades de acesso aos serviços de saúde.

O CPO-D aos 12 anos de idade foi de 2,5. Apesar de estar acima da média nacional, 2,1, o município apresentou uma condição de baixa prevalência de cárie dentária em 2010, segundo a classificação da OMS. Esta foi a única idade índice em que a maioria $(61,6 \%)$ apontou o serviço público como o mais utilizado.

Entre os adolescentes a média do CPO-D foi de 4,1, ligeiramente menor que a média nacional $(4,25)$, que representa um aumento considerável da média do agravo identificado aos 12 anos. Essa evolução da infância para a adolescência foi também observada nos dados nacionais e em outros municípios do Brasil.

Os adultos apresentaram uma média de CPO-D de 18 , superior à média nacional $(16,75)$, sendo classificado pela OMS como muito alto. Este grupo se destacou em se declarar insatisfeito ou muito insatisfeito com os dentes e com a boca (44\%). Apresentou também o maior percentual de necessidade de tratamento dentário relatado $(80,8 \%)$, maior necessidade de prótese dentária $(76,2 \%)$ e $33,8 \%$ atribuiu gravidade máxima para a dor pregressa.

O grupo etário dos idosos concentrou o maior CPO-D de todos os grupos, 28,9, próximo da média nacional, 27,53. Houve também grande necessidade de serviços de prótese $(70,4 \%)$. Apesar disso, mais da metade declarou que não apresentava necessidade de tratamento e a grande maioria não relatou dor recente.

A maior parte dos entrevistados revelou ter ido ao dentista, dentre os que tiveram acesso, o serviço odontológico particular foi o mais relatado. Para a maioria dos indivíduos o motivo da última consulta foi para tratamento e a consulta foi avaliada como boa.

No presente relatório foram abordados apenas os principais resultados, numa análise descritiva. Outras análises mais detalhadas e aprofundadas poderão ser realizadas a partir dos dados primários, de acordo com o interesse do município.

Enfim, espera-se que as informações aqui disponibilizadas neste relatório constituam mais um instrumento de gestão no Sistema Único de Saúde local e contribuam para a melhoria da atenção à saúde e da qualidade de vida dos seus munícipes.

Recomenda-se que novos levantamentos sejam realizados no município, a fim de que haja monitoramento das condições pesquisadas ao longo dos anos.

\section{Bibliografia}

1. Brasil. Ministério da Saúde. Divisão Nacional de Saúde Bucal. Levantamento Epidemiológico em Saúde Bucal: Brasil, zona urbana. Brasília: Ministério da Saúde; 1986. 137p.

2. Brasil. Ministério da Saúde. Secretaria de Atenção à Saúde. Departamento de Atenção Básica. Projeto SB Brasil 2003: condições de saúde bucal da população brasileira 20022003: resultados principais. Brasília: Ministério da Saúde; 2004. 68 p. Série C. Projetos, Programas e Relatórios.

3. Brasil. Ministério da Saúde. Secretaria de Atenção à Saúde. Departamento de Atenção Básica. Coordenação Nacional de Saúde Bucal. Diretrizes da Política Nacional de Saúde Bucal. Brasília: Ministério da Saúde; 2004. 
4. Cochran WG. Sampling techniques. 3rd ed. New York: John Wiley and Sons; 1977.

5. Cons NC, Jenny J, Kohout FJ, Songpaisan Y, Jotikastira D. Utility of the dental aesthetic index in industrialized and developing countries. J Pub Health Dent. 1989; 49(3):1636.

6. Dean HT. Classification of mottled enamel diagnosis. J Am Med Assoc. 1934; 21:14216.

7. Fejerskov O, Manji F, Baelum V, Möeler IJ. Fluorose dentária: um manual para profissionais de saúde. São Paulo: Santos; 1994. 122 p.

8. Foster TD, Hamilton MC. Occlusion in the primary dentition: study of children at $21 / 2$ to 3 years of age. British Dental Journal. 1969; 21: 76-79.

9. Frias AC, Antunes JLF, Narvai PC. Precisão e validade de levantamentos epidemiológicos em saúde bucal: cárie dentária na cidade de São Paulo, 2002. Rev Bras Epidemiologia 2004;7(2):144-54.

10. Gil C, Nakamae AEM. Índice de qualidade do trabalho protético (IQP): um estudo metodológico. Revista da Pós-Graduação. 2000; 7(1): 38-46.

11. Holmgren C. CPITN: Interpretations and limitations. Int Dent J. 1994; 44(5): 533-46.

12. Narvai PC, Antunes JLF, Moysés SJ et al. Validade científica de conhecimento epidemiológico gerado com base no estudo Saúde Bucal Brasil 2003. Cad Saúde Pública 2010; 26(4):647-70.

13. Roncalli AG. Levantamentos epidemiológicos em saúde bucal no Brasil. In: Antunes JLF, Peres MA. Epidemiologia da saúde bucal. Rio de Janeiro: Guanabara-Koogan. 2006. p.32-48.

14. Silva NN. Amostragem probabilística. 2 ed. São Paulo: EDUSP, 2001. 124p.

15. SPSS Inc. SPSS Complex Samples 15.0. Chicago: SPSS, 2006. 211p.

16. United Nations. Department of Economic and Social Affairs, Statistic Division. Household Sample Surveys in Developing and Transition Countries. New York: United Nations Publications; 2005. 655p.

17. World Health Organization. Calibration of examiners for oral health epidemiological surveys. Geneva: ORH/EPID; 1993.

18. World Health Organization. Oral health surveys: basic methods. 3 ed. Geneva: ORH/EPID; 1987.

19. World Health Organization. Oral health surveys: basic methods. 4 ed. Geneva: ORH/EPID; 1997. 
Anexo 1- Setores censitários sorteados - Anápolis-2010

\begin{tabular}{|c|c|}
\hline Item & Setor Censitário \\
\hline 1 & 520110805000091 \\
\hline 2 & 520110805000064 \\
\hline 3 & 520110805000226 \\
\hline 4 & 520110805000227 \\
\hline 5 & 520110805000213 \\
\hline 6 & 520110805000205 \\
\hline 7 & 520110805000249 \\
\hline 8 & 520110805000210 \\
\hline 9 & 520110805000005 \\
\hline 10 & 520110805000173 \\
\hline 11 & 520110805000081 \\
\hline 12 & 520110805000150 \\
\hline 13 & 520110805000139 \\
\hline 14 & 520110805000055 \\
\hline 15 & 520110805000082 \\
\hline 16 & 520110805000259 \\
\hline 17 & 520110805000114 \\
\hline 18 & 520110805000119 \\
\hline 19 & 520110805000185 \\
\hline 20 & 520110805000019 \\
\hline 21 & 520110805000129 \\
\hline 22 & 520110805000243 \\
\hline 23 & 520110805000198 \\
\hline 24 & 520110805000217 \\
\hline 25 & 520110805000244 \\
\hline 26 & 520110805000158 \\
\hline 27 & 520110805000080 \\
\hline 28 & 520110805000027 \\
\hline 29 & 520110805000252 \\
\hline 30 & 520110805000260 \\
\hline
\end{tabular}


Anexo 2 - Ficha de Exame e Questionário

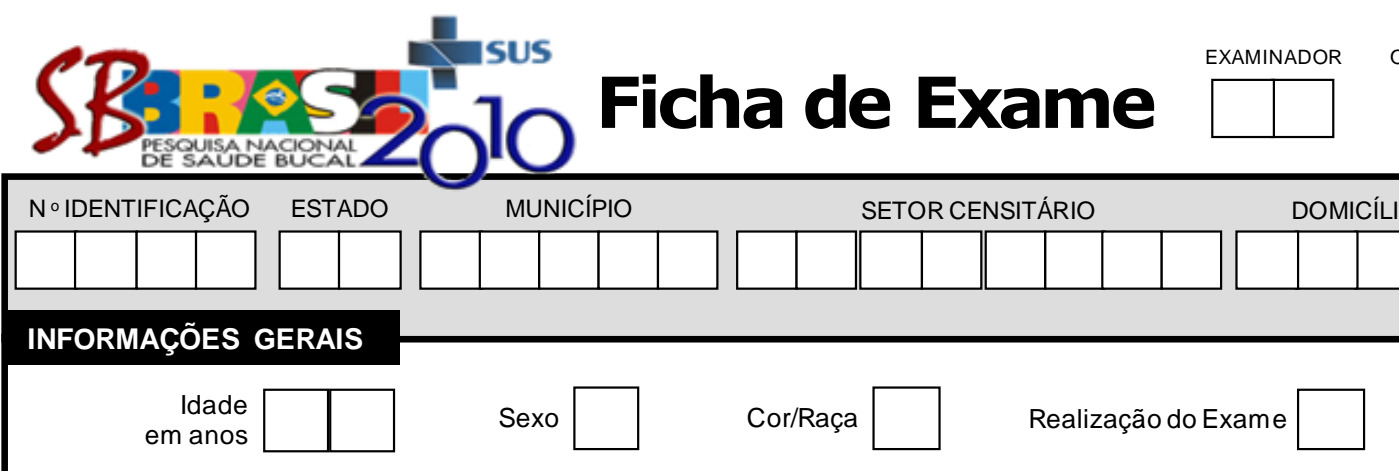

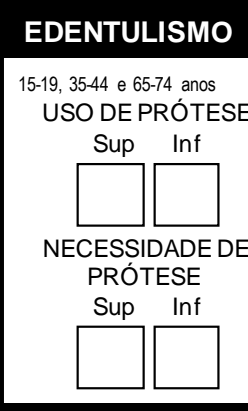

\section{FLUOROSE}

12 anos

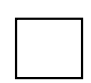

\section{CONDIÇÃO DA OCLUSÃO DENTÁRIA}

DAI

(12e 15 a 19 anos)

DENTIÇÃO

$\square \begin{aligned} & \text { Número de Incisivos, Caninos } \\ & \text { ePré-Molares perdidos }\end{aligned}$

ESPAÇO
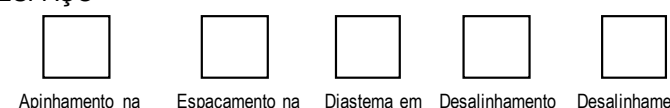

Espaçamento na Diastema em Desalinhamento Desalinhamento regiäo de incisivos regiäo de incisivos milimetros maxilar anterior mandibular OCLUSÃO
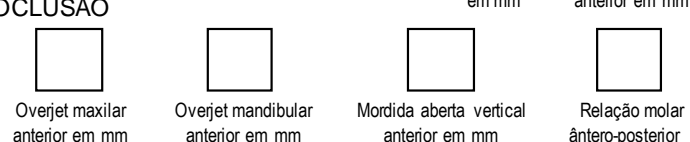

MÁ-OCLUSÃO

(5 anos)
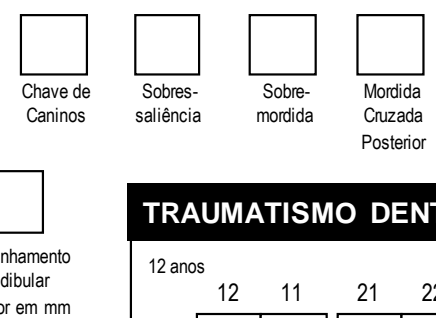

TRAUMATISMO DENTÁRIO

CÁRIE DENTÁRIA E NECESSIDADE DE TRATAMENTO

Todos os grupos etários. Condição de Raiz, somente de 35 a 44 e 65 a 74 anos
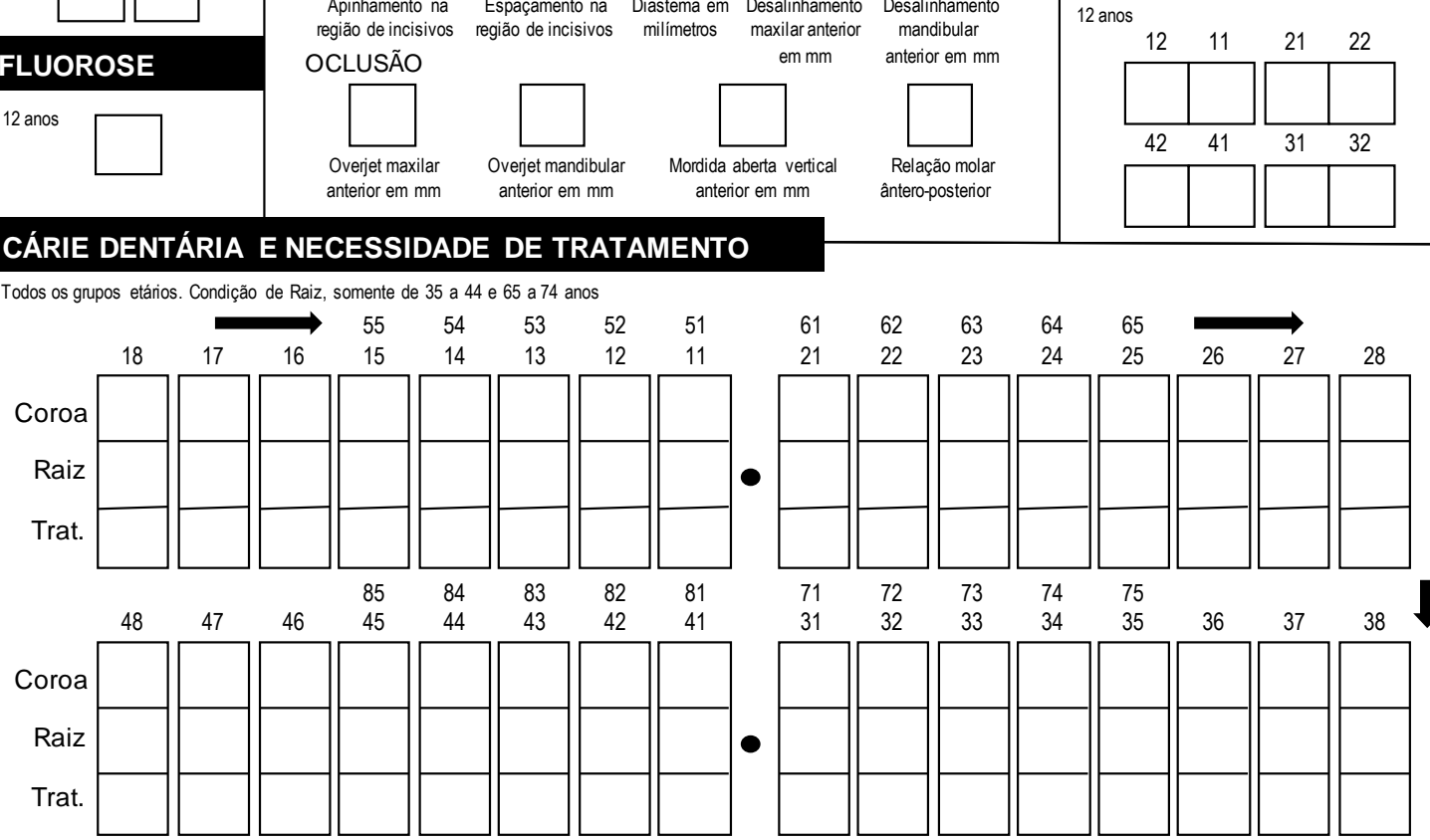

\section{CONDIÇÃO PERIODONTAL}

CPI: 12,15 a 19,35 a 44 e 65 a 74 anos PIP: 35 a 44 e 65 a 74 anos
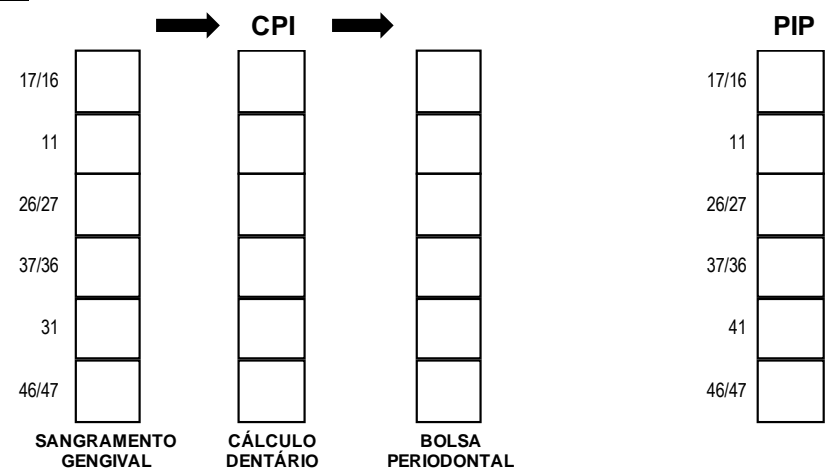


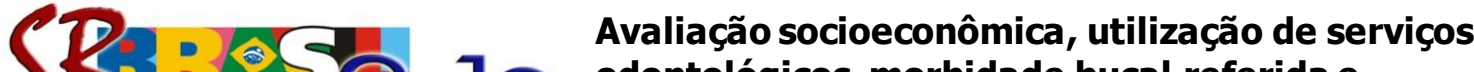 $\sin _{0,0}=$}

\section{CARACTERIZAÇÃo SOCIOECONÔMICA DA FAMÍLIA}

1 Quantas pessoas, incluindo você, residem nesta casa?

2 Quantos cômodos estão servindo permanentemente de dormitório para os moradores deste domicilio? Quantos bens tem em sua residência?

3 Considerar como bens: televisão, geladeira, aparelho de som, micro-ondas, telefone, telefone celular, máquina de lavar roupa, máquina de lavar louça, micro-computador, e número de carros. Varia de $\mathbf{0}$ a $\mathbf{1 1}$ bens. Marcar $\mathbf{9 9}$ para "não sabe / não respondeu" No mês passado, quanto receberam, em reais, juntas, todas as pessoas que moram na sua casa incluindo salários, bolsa família, pensão, aluguel, soldo, aposentadoria ou outros rendimentos?

4 1-Até 250; 2-De 251 a 500; 3-De 501 a 1.500; 4-De 1.501 a 2.500; 5-De 2.501 a 4.500; 6-De 4.501 a 9.500; 7-Mais de 9.500; 8-Não se aplica; 9 -Não sabe/não respondeu

\section{ESCOLARIDADE, MORBIDADE BUCAL REFERIDA E USO DE SERVIÇOS}

Até que série o sr(a) estudou?

5 1-Não estudei na escola; 2-Fiz curso de alfabetização de adultos; 3-Até a 4a, série do ensino fundamental; 4-Até a $8^{a}$. série do ensino

6 O sr(a) acha que necessita de tratamento dentário atualmente? 0-Não; 1-Sim; 8-Não se aplica; 9-Não sabe / Não respondeu

7 Nos últimos 6 meses o sr(a) teve dor de dente? 0-Não; 1-Sim; 8-Não se aplica; 9-Não sabe / Não respondeu

8 Aponte na linha ao lado o quanto foi esta dor $\mathbf{1}$ (um) significa muito pouca dore $\mathbf{1 0}$ (dez) uma dor muito forte

9 Alguma vez na vida o sr(a) já foi ao consultório do dentista? 0-Não; 1-Sim; 8-Não se aplica; 9-Não sabe / Não respondeu

10 Quando você consultou o dentista pela última vez?

1-Menos de um ano; 2-Um a dois anos; 3-Três anos ou mais; 8-Não se aplica; 9-Não sabe / Não respondeu

11 Onde foi a sua última consulta?

1-Serviço público; 2-Serviço particular; 3-Plano de Saúde ou Convênios; 4-Outros; 8-Não se aplica; 9-Não sabe / Não respondeu

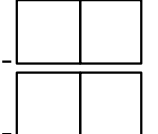

12 Qual o motivo da sua última consulta?

12 1-Revisão, prevenção ou check-up; 2-Dor; 3-Extração; 4-Tratamento; 5-Outros; 8-Não se aplica; 9-Não sabe / Não respondeu

3 O que você achou do tratamento na última consulta?

1-Muito Bom; 2-Bom; 3-Regular; 4-Ruim; 5-Muito Ruim; 8-Não se aplica; 9-Não sabe / Não responde

\section{AUTOPERCEPÇÃO E IMPACTOS EM SAÚdE BUCAL}

14 Com relação aos seus dentes/boca o sr(a) está:

1-Muito satisfeito; 2-Satisfeito; 3-Nem satisfeito nem insatisfeito; 4-Insatisfeito; 5-Muito insatisfeito; 8-Não se aplica; 9-Não sabe / Não responde

5 O sr(a) considera que necessita usar prótese total (dentadura) ou trocar a que está usando atualmente? 0-Não; 1-Sim; 8-Não se aplica; 9-Não sabe / Não respondeu

16 Algumas pessoas têm problemas que podem ter sido causados pelos dentes. Das situações abaixo, quais se aplicam a(o) sr(a), nos últimos seis meses? 0-Não; 1-Sim; 8-Não se aplica; 9-Não sabe / Não respondeu

16.1. Teve dificuldade para comer por causa dos dentes ou sentiu dor nos dentes ao tomar liquidos gelados ou quentes?

16.2. Os seus dentes o incomodaram ao escovar?

$$
\text { -16.--0s seus denteso deixaramnervoso(a) ou }
$$

16.3. Os seus dentes o deixaram nervoso (a) ou irritado (a)?

16.4. Você deixou de sair, se divertir, ir a festas, passeios por causa dos seus dentes?
16.5. Você deixou de praticar esportes por causa dos seus dentes?

16.6. Você teve dificuldade para falar por causa dos seus dentes?

16.7. Os seus dentes o fizeram sentir vergonha de sorrir ou falar? - - - - -

16.8. Os seus dentes atrapalharam para estudar/ trabalhar ou fazer tarefas da escola / trabalho?

16.9. Você deixou de dormir ou dormiu mal por causa dos seus dentes?
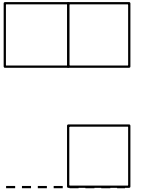
Anexo 3 - Termo de Consentimento Livre e Esclarecido

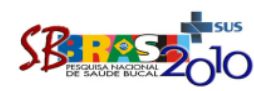

\section{Termo de Consentimento Livre e Esclarecido}

\section{Esclarecimentos}

Este é um convite para você participar da Pesquisa Nacional de Saúde Bucal (Projeto SBBrasil 2010) realizada pelo Ministério da Saúde em parceria com as Secretarias de Estado da Saúde, Secretarias Municipais, Entidades Odontológicas e Universidades.

Sua participação é voluntária, o que significa que você poderá desistir a qualquer momento, retirando seu consentimento, sem que isso lhe traga nenhum prejuízo ou penalidade.

Nessa investigação científica, serão examinados os dentes e as gengivas de crianças e adultos da população do seu município, escolhidos por sorteio. O exame é uma observação da boca, feita na própria escola ou na residência, com toda técnica, segurança e higiene, conforme normas da Organização Mundial da Saúde e do Ministério da Saúde. Não representa riscos nem desconforto para quem será examinado. Os dados individuais não serão divulgados em nenhuma hipótese, mas os resultados da pesquisa ajudarão muito a prevenir doenças bucais e melhorar a saúde de todos. Os riscos relativos à sua participação nesta pesquisa são mínimos e os benefícios que você terá serão indiretos e relacionados a um melhor conhecimento a respeito das doenças bucais na população brasileira de modo a organizar os serviços de maneira mais racional e efetiva.

Todas as informações obtidas serão sigilosas e seu nome não será identificado em nenhum momento. Os dados serão guardados em local seguro e a divulgação dos resultados será feita de forma a não identificar os voluntários. Se você tiver algum gasto que seja devido à sua participação na pesquisa, você será ressarcido, caso solicite. Em qualquer momento, se você sofrer algum dano comprovadamente decorrente desta pesquisa, você terá direito a indenização.

Caso seja detectado algum problema de saúde bucal que exija atendimento odontológico, você será devidamente encaminhado a uma Unidade de Saúde, onde será atendido.

Você ficará com uma cópia deste Termo e toda a dúvida que você tiver a respeito desta pesquisa, poderá perguntar diretamente para Fabíola Fernandes Soares, no endereço <RUA PROFESSOR ROBERTO MANGE, $152,4^{\circ}$. ANDAR, CENTRO, ANÁPOLIS-GO, CEP: 75.024-090.>, ou pelo telefone <(62) 3902-2756>.

Dúvidas a respeito da ética dessa pesquisa poderão ser questionadas ao Comitê de Ética em Pesquisa do Ministério da Saúde no endereço <COMISSÃO NACIONAL DE ÉTICA EM PESQUISA - CONEP UNIDADE II MINISTÉRIO DA SAÚDE SEPN 510 NORTE BLOCO A $1^{\circ}$ SUBSOLO - EDIFÍCIO EXINAN. > ou pelo telefone< (61) 3315-5878>.

Consentimento Livre e Esclarecido - Para participante individual

Declaro que compreendi os objetivos deste estudo, como ele será realizado, os riscos e benefícios envolvidos na Pesquisa Nacional de Saúde Bucal - Projeto SBBrasil 2010 e autorizo a realização do exame

Data 1

Nome em letra de forma

$\overline{\text { Assinatura ou impressão dactiloscópica }}$

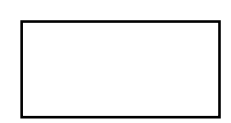

Consentimento Livre e Esclarecido - Para Pais ou Responsáveis

Declaro que compreendi os objetivos deste estudo, como ele será realizado, os riscos e benefícios envolvidos na Pesquisa Nacional de Saúde Bucal - Projeto SBBrasil 2010 e autorizo a realização do exame em

\section{Responsável} Data / /

Nome em letra de forma

Assinatura ou impressão dactiloscópica

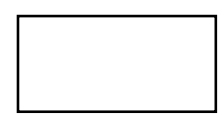

\section{Pesquisador}

Nome em letra de forma

Assinatura 